\title{
WestVirginiaUniversity
}

THE RESEARCH REPOSITORY @ WVU

Graduate Theses, Dissertations, and Problem Reports

2002

\section{Experimental study of thermosiphon performance}

Sumeeth S. Sivanagere

West Virginia University

Follow this and additional works at: https://researchrepository.wvu.edu/etd

\section{Recommended Citation}

Sivanagere, Sumeeth S., "Experimental study of thermosiphon performance" (2002). Graduate Theses, Dissertations, and Problem Reports. 1262.

https://researchrepository.wvu.edu/etd/1262

This Thesis is protected by copyright and/or related rights. It has been brought to you by the The Research Repository @ WVU with permission from the rights-holder(s). You are free to use this Thesis in any way that is permitted by the copyright and related rights legislation that applies to your use. For other uses you must obtain permission from the rights-holder(s) directly, unless additional rights are indicated by a Creative Commons license in the record and/ or on the work itself. This Thesis has been accepted for inclusion in WVU Graduate Theses, Dissertations, and Problem Reports collection by an authorized administrator of The Research Repository @ WVU. For more information, please contact researchrepository@mail.wvu.edu. 
Experimental Study of Thermosiphon Performance

\author{
Sumeeth S. Sivanagere
}

Thesis submitted to the College of Engineering and Mineral Resources

At West Virginia University

In partial fulfillment of the requirements

for the degree of

\author{
Master of Science \\ In \\ Mechanical Engineering \\ John M. Kuhlman, Ph.D., Chair \\ Donald D. Gray, Ph.D. \\ Gary J. Morris, Ph.D.
}

Department of Mechanical and Aerospace Engineering

\author{
Morgantown, West Virginia \\ 2002
}




\section{ABSTRACT \\ Experimental Study of Thermosiphon Performance}

\section{Sumeeth S. Sivanagere}

A model single phase loop thermosiphon was designed and built such that velocity profiles and heat transfer rates could be studied by obtaining temperature data, along with a detailed set of non-intrusive Laser Doppler Velocimetry measurements. The quantities measured were the instantaneous velocity profiles for the water flow. These velocities were then reduced into sets of mean and root mean square velocities, for different angles of tilt of the experimental setup. Nominal heating and cooling rates were held constant.

The single phase thermosiphon consisted of an aluminum flow loop, fitted with a test section made of Plexiglas, that was rectangular in cross section. The entire pipe loop was filled with distilled water for this set of experiments. Flow was generated by thermoelectric coolers fixed on both sides of the top leg and thermoelectric heaters fixed on both sides of the bottom leg of the thermosiphon. The flow direction was reversed by changing the angle of tilt of the experimental setup. The data were taken across the 1.5 inch and 0.75 inch dimensions of the test section at both the center and at the right end of the wall as tilt angle was varied from 3.6 degrees clockwise to 4.2 degrees counter clockwise.

The predicted velocities from a one dimensional flow model were 3-4 times bigger than the observed mean velocities. Average heating rate was 70 Watts, while measured average cooling rate was 27 Watts. RMS velocities were typically $10-20 \%$ of the mean velocities. It was found that the mean velocity profiles across the 1.5 inch dimension of the flow area were consistently higher near the back wall and lower near the front wall of the test section. 


\section{ACKNOWLEDGEMENTS}

This work has been supported by a NASA EPSCOR Planning Grant awarded by WV Space Grant Consortium and partly by the WVU MAE Dept.

I would like to extend my sincere appreciation to all those who made this accomplishment possible. First I would like to thank Dr. John Kuhlman for having confidence and faith and willingness to spend all that time with me and giving me the opportunity to work on this project. I would like to thank specifically Dr. Donald Gray and Dr. Gary Morris for sharing their technical expertise with me and for serving on my committee. A special thanks goes to the Mechanical and Aerospace Engineering department and all the faculty and staff associated with my Master's degree.

I would also like to thank everyone who has assisted me on this project, including Chuck Coleman, Cliff Judy and Tony.

My deepest thanks and gratitude go out to my parents Shantharaju and Kamala Raju, my sister Sushma and brother in law Shravan Kumar. Without your love and support, I would not be here today.

Finally to my wonderful wife Swapna, it is you who supported and stood by me through all the difficulties of this project. Without your true love I would have not accomplished what I have now. I dedicate this thesis to you. 


\section{TABLE OF CONTENTS}

PAGE

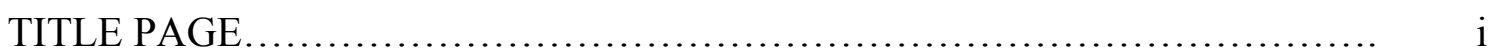

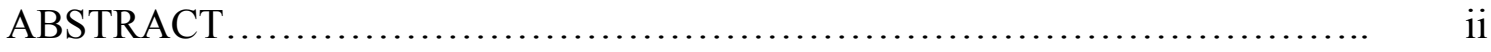

ACKNOWLEDGEMENTS ................................................ iii

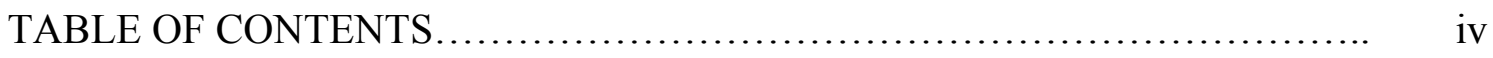

LIST OF FIGURES.............................................................................

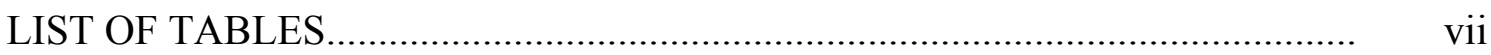

CHAPTER1.0 INTRODUCTION................................................................. 1

CHAPTER2.0 LITERATURE REVIEW ............................................................

CHAPTER3.0 APPARATUS AND PROCEDURE............................................ 8

3.1 Experimental Apparatus................................................................... 8

3.2 Laser Doppler Velocimetry............................................................ 10

3.3 Operation procedure For Thermosiphon............................................... 12

3.4 LDV Alignment Procedure.................................................................. 12

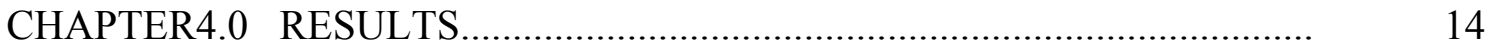

4.1 Results for downflow of liquid........................................................ 14

4.2 Results for the upflow of liquid.......................................................... 19

4.3 Results for the upflow of liquid with zero tilt...................................... 21

4.4 Results for various angles of tilt........................................................ 23

CHAPTER5.0 DISCUSSION, CONCLUSIONS AND RECOMMENDATIONS 25

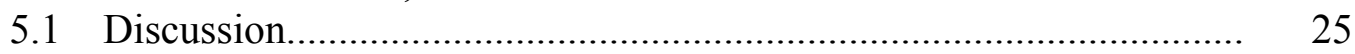

5.2 Conclusions .............................................................................. 26

5.3 Recommendations........................................................................ 27

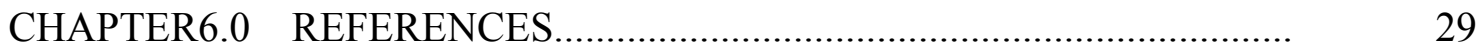

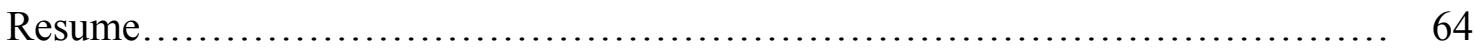




\section{LIST OF FIGURES}

Figure $\quad$ Page

$2.1 \quad$ Closed loop thermosiphon...................................... 30

3.1 Overview of thermosiphon, LDV system and traverse table...................... 31

3.2a Front view of the thermosiphon mounted on the aluminum frame............. 32

$3.2 \mathrm{~b} \quad$ Rear view of the thermosiphon with aluminum frame.............................. 33

3.3 Line drawing of the test section.......................................................... 34

3.4 AutoCAD drawing of the thermosiphon.............................................. 35

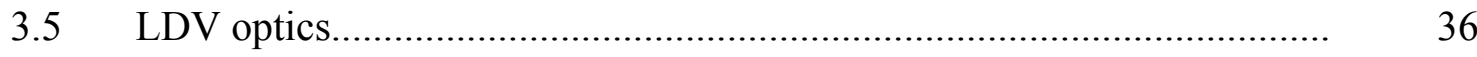

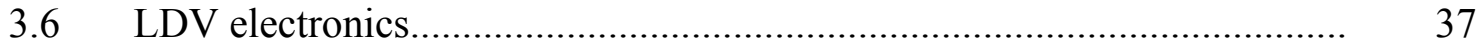

4.1.1 LDV data versus dimensionless distance for 1.5 inch traverse

(Run \# 1; downflow; 2.2 deg ccw tilt)................................................ 38

4.1.2 LDV data versus dimensionless distance for 0.5 inch traverse

(Center) (Run \# 1 downflow; 2.2 deg ccw tilt)...................................... 39

4.1.3 LDV data versus dimensionless distance for 0.5 inch traverse

(Right end) (Run \# 1; downflow; 2.2 deg ccw tilt)................................ 40

4.1.4 LDV data series for the different traverses

(Run \#1; downflow; 2.2 deg ccw tilt).

4.2.1 LDV data versus dimensionless distance for 1.5 inch traverse

(Run \# 2; downflow; 2.2 deg ccw tilt).

4.2.2 LDV data versus dimensionless distance for 0.5 inch traverse

(Center) (Run \# 2; downflow; 2.2 deg ccw tilt)....

4.2.3 LDV data versus dimensionless distance for 0.5 inch traverse

(Right end) (Run \# 2; downflow; 2.2 deg ccw tilt).

4.2.4 LDV data series for different traverses

(Run \#2; downflow; 2.2 deg ccw tilt) 
4.2.5 Variation of temperature with respect to time for different traverses ( run \#2; downflow; 2.2 deg ccw tilt)....................................................... 46

4.3.1 LDV data versus dimensionless distance for 1.5 inch traverse (Run \# 3; upflow; 2.1 deg cw tilt)............................................................. 47

4.3.2 LDV data versus dimensionless distance for 0.5 inch traverse (Center) (Run \# 3; Upflow; 2.1 deg cw tilt).............................................. 48

4.3.3 LDV data versus dimensionless distance for 0.5 inch traverse (Right end) (Run \# 3; Upflow; 2.1 deg cw tilt ).

4.3.4 LDV data series for different traverses (run \#3; upflow; $2.1 \mathrm{deg} \mathrm{cw}$ tilt)... $\quad 50$

4.3.5 Variation of temperature with respect to time for different traverses ( run \#3; upflow; 2.1 deg cw tilt).

4.4.1 LDV data versus dimensionless distance for 1.5 inch traverse (Run \# 4; upflow; 2.1 deg cw tilt).

4.4.2 LDV data versus dimensionless distance for 0.5 inch traverse (Center) (Run \# 4; Upflow; 2.1 deg cw tilt).

4.4.3 LDV data versus dimensionless distance for 0.5 inch traverse (Right end) (Run \# 4; Upflow; 2.1 deg cw tilt )

4.4.4 LDV data series for different traverses ( run \#4; upflow; 2.1 deg cw tilt).. $\quad 55$

4.4.5 Variation of temperature with respect to time for different traverses (Run \#4; upflow; 2.1 deg cw tilt).

4.5.1 LDV data versus dimensionless distance for 1.5 inch traverse (Run \# 5; Upflow; $0 \pm 0.1$ deg tilt).

4.5.2 LDV data series for 1.5 inch traverse at different locations (Run \# 5; Upflow; $0 \pm 0.1$ deg tilt)

4.5.3 Variation of temperature with respect to time for $1.5 \mathrm{inch}$ traverse (Run \# 5; Upflow; $0 \pm 0.1$ degree tilt of the setup).

4.6.1 LDV data on the centerline for various angles of tilt of the setup......... 60 


\section{LIST OF TABLES}

TABLE

4.1 Summary of results for different runs............................................ 61

4.1 Summary of results for various angles of tilt........................................ 62

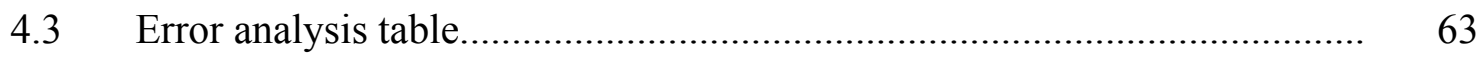




\section{Chapter 1: INTRODUCTION}

A nonuniform magnetic field exerts a body force on all magnetically permeable materials called the Kelvin force. The Kelvin force is independent of the fluid's electrical conductivity. The Kelvin force tends to move paramagnetic materials toward and diamagnetic materials away from higher magnetic field regions (Rosensweig, 1985). Gradients in the Kelvin force due to magnetic susceptibility gradients can drive convection, similar to conventional gravitational buoyancy driven convection. Temperature gradients then can cause convection in microgravity because susceptibility depends explicitly on density for both paramagnetic and diamagnetic fluids, and explicitly on temperature for paramagnetic fluids.

A thermosiphon is a circulating fluid system (pipe loop or open cavity) that uses differential heating to establish a buoyancy driven flow for the purpose of transporting thermal energy. Thermosiphons are used in a wide range of engineering applications. The important applications that can be quoted are solar, geothermal, nuclear, gas turbine, and electronic industries (Mertol and Greif, 1985).

The purpose of this project was the experimental study of thermospihon performance. The specific objectives of this project were: 1. To design and build a rectangular loop thermosiphon, and 2 . To obtain detailed velocity measurements using a state-of-the-art Argon-ion Laser Doppler Velocimeter. The Laser Doppler Velocimeter is advantageous in that it is a non-intrusive measurement technique, and does not alter the flow as would intrusive probe methods. Further, it can correctly respond to flow reversals when a Bragg cell is used. The statistical quantities that were investigated include profiles 
of: mean velocity, root-mean-square velocity and turbulence intensity of the liquid, midway along one of the vertical legs of the thermosiphon, measured across both dimensions of the test section flow area. It is hoped that this study will be a preliminary step in a planned experiment to document the performance of a magnetothermosiphon, where the convective flow will be driven by the Kelvin force through use of a strong permanent magnet, with a solution of manganese chloride in water as the paramagnetic working fluid. Magnetothermal convection has been previously demonstrated by Carruthers and Wolfe (1968). 


\section{Chapter 2: LITERATURE REVIEW}

\section{Introduction:}

A thermosiphon can be defined as a circulating fluid system that uses differential heating to establish a buoyancy driven flow for the purpose of transporting thermal energy. Thermosiphons are used in a wide variety of applications such as solar power production, gas turbine, geothermal applications, electronic industries, nuclear applications and many more. Japikse (1973) and Mertol and Greif (1985) have performed surveys of experimental and theoretical studies of three basic geometries: pipe loops, closed cavities, and open cavities.

Thermosiphons can be classified in many ways. According to Davies and Morris (1965) thermosiphons can be categorized based on:

A. The nature of boundaries (if the system is open or closed to mass flow).

B. The regime of heat transfer (if the process is purely natural convection or mixed natural and forced convection).

C. The number of phases present (if it is a single phase or two-phase system).

D. The nature of the body force (if it is gravitational or rotational).

\section{Open Thermosiphons}

An open system is in the form of a tube that is open at the top and closed at the bottom. Heating the wall of an open thermosiphon causes an upward flow along the wall due to buoyancy effects and a return flow downward in the core via continuity. For larger heat fluxes buoyancy forces are more intense near the wall and a boundary layer regime is obtained. For weaker heat fluxes buoyancy forces become less and the effect of shear is 
relatively enhanced which causes the boundary layer to fill the entire tube (Japikse, 1973).

\section{Closed Thermosiphons}

A closed system is in the form of a tube that is closed at both the ends. The closed loop thermosiphons gained quick popularity since the problems with containment, chemical compatibility and pressurization became more apparent in the various applications of the open thermosiphons (Japikse, 1973).

When a closed loop thermosiphon is modeled carefully it can be treated as two simple open thermosiphons joined at the midtube exchange region. Most of the modes of flow found for the open thermosiphons are found in closed thermosiphons. The main exception is that the impeded turbulent flow is reduced considerably.

\section{Natural Convection Loops}

In natural convection thermosiphons the density difference between the heated and cooled portions of the loop causes the fluid flow. Natural circulation loops have been used in a variety of applications such as solar energy heating and cooling systems, geothermal power production, permafrost protection, turbine blade cooling, engine and computer cooling applications.

The velocity and temperature profiles in these loops often indicate the presence of reverse flows and oscillations. The amplitude of the profiles may stay stable, may decay or may amplify (Nyce and Rosenberger, 1995).

\section{Two-Phase Thermosiphons}

The advantages of operating a two-phase thermosiphon are high heat fluxes associated with the latent heats of evaporation and condensation, the much lower 
temperature gradients associated with these processes, and the reduced weight of such a system over a similar liquid system. Schmidt (1951) capitalized on the high heat transfer and the low temperature gradients and regulated the pressure in his open thermosiphon turbine blade so that boiling would occur at the free surface giving a very efficient heat sink. Cohen and Bayley (1955) took advantage of using small fillings with their rotating and static experiments and found that very good heat transfer could be obtained with as little as $1.5 \%$ volume filling of their system.

\section{Closed Loop Thermosiphons}

The study of closed loop thermosiphons has been profitable due to several reasons. First, it is a very natural geometric configuration that can be found or created easily in many industrial situations. Secondly, it avoids the entry choking or mixing that occurs in the open thermosiphon, the complex midtube exchange process in a closed thermosiphon and, largely, the adverse core-boundary layer interaction common to both the open and closed thermosiphons (Japikse 1973). In principle, there is virtually no limit to the types of flow that could be obtained in a closed loop subject to various thermal, geometric, body force, and thermodynamic state conditions.

Consider a closed-loop thermosiphon (see Fig. 2.1) in which the equal top wall temperatures $\left(T_{3}=T_{4}\right)$ are less than the equal bottom wall temperatures $\left(T_{1}=T_{2}\right)$ and the geometry in all sections identical (no rotation or tilt). In this event each side of the loop would behave virtually independently as a simple closed thermosiphon with no appreciable circulation between the two sides. If, however, a significant change is made in the constraints, such as geometry or wall temperatures, then a strong loop circulation can be induced (Japikse 1973). 
The analyses were for the determination of transient velocity, pressure and temperature profiles in a toroidal natural circulation loop was done by Mertol and Greif (1985). The loop was heated continuously by a constant heat flux over the bottom half of its area and was cooled continuously over the top half by transfering heat to the surface which was maintained at a constant temperature.

The three-dimensional analysis predicted the regions of streamwise flow reversal. When the flow entered the cooling section, the fluid near the pipe wall was suddenly cooled, became heavier and fell. Similarly when the flow entered the heating section the fluid near the wall was suddenly heated, and would rise. Flow reversal has been observed in the cooling section by Damerell and Schoenhals (1979).

This analysis also predicted secondary motion, that is, non-zero cross-stream velocity components. Near the pipe walls the fluid moved toward the center of curvature, and near the pipe center it moved away from the center of curvature.

The three-dimensional analysis predicts axial velocity and temperature profiles, which are not symmetric about the pipe centerline; that is, they are non-axisymmetric. Non-axisymmetric velocity profiles have been observed in the region of flow reversal by Damerell and Schoenhals (1979).

Acosta, Sen, and Ramos (1987) studied the natural circulation of water in a tilted square loop thermosiphon of circular cross section. The experimental device used was a square loop of side $0.5 \mathrm{~m}$ with a $20 \mathrm{~mm}$ diameter circular cross section mounted on a vertical frame that permitted rotation around its horizontal axis. Two opposite sides of the square were copper pipes while the other two were Pyrex glass and PVC tubes, respectively. The experimental results obtained were classified into two sets: 1 . Zero tilt 
angle cold start 2. Variable tilt angles. In the experiments carried out at zero tilt angle, the heat input on the bottom leg was varied from 7.4 to 210 watts. In the majority of the runs, the working fluid rotated in the counterclockwise direction. On monitoring the temperature it was observed that for low heat inputs a constant steady state was reached whereas for large heat inputs a noisy state was obtained.

It was observed that in a certain range of inclinations around zero degrees, both clockwise and counterclockwise motions were possible. On exceeding a certain tilt angle, an antinatural flow suddenly changed direction to adopt a natural flow direction. The critical tilt angle $\alpha_{c}$, which forms the boundary between stable single and multiple steady states was dependent on the heat flux. At low heat inputs the critical angle could be as large as 25 degrees and consequently was much easier to observe. For a heat input of 0.83 Watts the critical angle was around 35 degrees, for a heat input of 7.5 Watts around 30 degrees and for a heat input of 83 Watts it was around 5-6 degrees.

The passage of flow from the curved into the straight section at the exit to a bend causes an increase of the pressure at the inner wall and its decrease at the outer wall. Therefore the flow velocity will correspondingly be lower at the inner wall and larger at the outer wall (Handbook of hydraulic resistance, second edition, Idelchik, 1986). 


\section{Chapter 3: Apparatus and Procedure}

\section{Section 3.1: Experimental Apparatus}

Fig 3.1 shows an overview of the complete experimental setup, which includes the thermosiphon, laser and traverse, LDV optics, LDV electronics, data acquisition computer, and the TEC power supplies.

The experimental single-phase loop thermosiphon was designed and constructed such that the Laser Doppler Velocimetry (LDV) measurements could be obtained for various tilt angles of the setup. Variables such as effects on LDV signal-to-noise ratio, errors in the positioning of the test section and, cost and availability of the materials were considered before the single-phase thermosiphon was constructed. Thermosiphon height to width ratio was similar to that of Acosta, Sen and Ramos (1987). The resulting facility (Fig. 3.2a and 3.2b) consisted of a rectangular pipe loop with a test section made of Plexiglas of rectangular flow cross section. The pipe loop was made of welded aluminum, and the test section was made of Plexiglas. Thermosiphon geometry was selected for optimal optical access for LDV system. The test section (Fig. 3.3) was located midway along one of the vertical legs of the pipe loop, as may be seen in Fig. 3.2a. The pipe loop was mounted on an aluminium frame $63.5 \mathrm{~cm}$ (25 inches) tall, 24.13 $\mathrm{cm}$ (9.5 inches) wide and $0.635 \mathrm{~cm}(0.25$ inch) thick. The base was $25.4 \mathrm{~cm}$ (10 inches) wide, $59.7 \mathrm{~cm}$ (23.5 inches) long and $1.27 \mathrm{~cm}(0.5$ inch) thick. A hinged joint was provided at $12.7 \mathrm{~cm}$ ( 5 inches) from the base to facilitate the positioning of the frame in both the vertical and horizontal positions (see Fig. 3.4). A series of holes with a spacing of $5.08 \mathrm{~cm}$ ( 2 inches) between them were located on both the vertical legs of the frame to enable the mounting of the pipe loop at different locations. A slot was cut on the top hole 
of the right leg to enable the clamping of the experimental setup at different angles of tilt. Four digital thermometers were mounted on the pipe loop: two on the bottom leg and two on the top leg, on both sides of the heaters/coolers, to make temperature measurements (see Fig. 2.1). An air vent was provided on the left side of the top leg to enable the liquid to fill the entire pipe loop. Two valves were used: one at the top and the other at the bottom, to fill and drain the liquid, respectively. A plastic funnel was used to fill the distilled water into the pipe loop. A plastic tube was connected from the bottom of the funnel to one end of the valve, which regulated the liquid flow. The other end of the valve was connected via plastic tubing to brass hose barb on the top of the pipe loop. An other valve regulated the drain flow of the liquid from the bottom of the pipe loop.

Thermoelectric coolers (TECs) (manufactured by Ferrotec America Corporation, Module number 6301/127/040 with Qmax=38.0 watts) were mounted on both the top and bottom legs of the pipe loop to generate a buoyancy driven natural convection flow. For the bottom leg two thermoelectric coolers were mounted on the top face and two on the bottom face of the leg. The two right thermoelectric coolers for the bottom leg were in series with each other and the two left thermoelectric coolers of the bottom leg were in series with each other. The left pair of thermoelectric coolers were in parallel to the right pair of thermoelectric coolers. These four thermoelectric coolers were actually run as heaters in the present experiments. For the top leg, the two thermoelectric coolers on the top face were in series with each other and the two thermoelectric coolers on the bottom face were in series with each other. The top pair of thermoelectric coolers were in parallel to the bottom pair of thermoelectric coolers. This was done to balance the electrical loads 
with the available DC power supplies. The thermoelectric coolers were mounted to the pipe loop using two mini bar clamps (see Fig. 3.2a,b). Heat sinks were clamped on both faces of the thermoelectric coolers mounted to both the top and the bottom leg to increase the air-side heat transfer. Also, two PC blower fans (one for the top leg and the other for the bottom leg) were mounted using zip ties to increase the efficiency of heat transfer from the heat sinks to the room air. Two separate DC power supplies (manufactured by ASTRON, model no VLS-25M, output range 5-32 Volts DC, maximum current-25 Amps) were used to power the thermoelectric coolers or heaters on the top and the bottom leg. Generally, both the thermoelectric heaters and thermoelectric coolers were operated at nominally $20 \mathrm{~V}, 5 \mathrm{~A}$.

\section{Section 3.2: Laser Doppler Velocimetry}

Laser Doppler Velocimetry is a non-intrusive laser-based velocity measurement technique (Durst, Melling and Whitelaw, 1981). In this measurement technique, two coherent laser beams are focused to intersect at a point within the flow to form a series of interference fringes at the focal point. A seeding material is also introduced into the flow to provide scattering sites for the laser light. The seed material has several requirements such as the particles must be small enough to follow the flow, and must be neutrally buoyant. In many instances, natural particles in the flow facility have been used. Also, for some runs microbaloons were used as seeding particles in the flow to get the present measurements. The laser light scattered from these seed particles is then focused onto a photodetector such as a photomultiplier tube (PMT). This scattered light displays a periodic variation of high to low intensity that is due to the particles passing through the 
interference fringes formed in the probe volume where the two laser beams cross. Velocity perpendicular to the fringes is obtained from the frequency of this oscillating light intensity $\left(f_{D}=2 * u_{x} * \operatorname{sink} / \lambda\right.$ ) (TSI, Laser Velocimetry Systems) where $u_{x}$ is perpendicular to the bisector of the two illuminating beams and in the same plane, $\lambda=$ wavelength of laser light. The measuring diameter was $34.71 \mu \mathrm{m}$ and the measuring length was $143.16 \mu \mathrm{m}$.

Laser Doppler Velocimetry can determine if the flow direction is positive or negative with the help of a Bragg cell. A TSI Model 9182-3A (Fig.3.5) Optics Module has been used in the present LDV system. The model 9182-3A Optics Module contains an acousto-optic modulator (Bragg cell) that shifts the frequency of a laser beam by a fixed amount of 40 Megahertz. The acousto-optic modulator, that is enclosed within a cylindrical housing and is typically positioned after the beam splitter, shifts one of the beams so that a Doppler shift frequency is measured for stationary scattering sites. This frequency shift due to the Bragg cell should be larger than the frequency shift corresponding to the largest expected velocity.

The Bragg cell is driven by a 40 Megahertz, 2-watt signal supplied by a power amplifier (TSI model 9186). A 6-foot cable connects the optics module to the electronics module (Fig. 3.6). The electronics module is powered by $120 \mathrm{~V} \mathrm{AC}$ at 60 hertz. It contains a downmix circuit. Since a frequency shift of 40 Megahertz is generally greater than required, the downmix circuit allows one to decrease the effective frequency shift of 
the photodetector output to values from 10 Megahertz down to 2 Kilohertz. For the present work, generally an effective frequency shift of $50 \mathrm{kHz}$ has been used.

\section{Section 3.3: Operation Procedure for Thermosiphon}

The following steps were used for proper operation of the thermosiphon:

1. Level the thermosiphon.

2. Set and measure the tilt angle.

3. Turn on the heaters, coolers and PC fans.

4. Allow the system to reach steady state operation at a nominal temperature of 50 degrees $\mathrm{C}$.

5. Begin LDV data acquisition, recording four temperatures and air temperature for each LDV data point.

\section{Section 3.4: LDV Alignment Procedure}

The following steps were used to align the LDV optics module to get the best signal to noise ratio for the Doppler signal:

1. The focusing lens was removed and the optics module was rotated so that the acousto-optic modulator was outside the path of both laser beams.

2. Using the alignment mask the alignment of the entire optics module was optimized.

3. The electronics module was switched on.

4. The RF potentiometer on the electronics module was adjusted for the maximum intensity of the shifted beam.

5. The focusing lens was replaced and checked for beam crossing. 
6. The photodetector mount was adjusted to ensure that the scattered light was collected from the probe volume by the photomultiplier tube. Also, the backscatter focusing lens was optimized to obtain as sharp an image of the probe volume as possible.

7. The frequency shift button on the electronics module was set to 50 kilohertz, and shift direction was set to "up" or "down" as desired, so that the frequency shift direction was opposite to the expected velocity direction.

8. The signal processor gain and high pass and low pass filters were adjusted using standard procedures. 


\section{Chapter 4: Results}

This section presents the results for the data recorded and analyzed for the different thermosiphon runs. The data recorded for the 1.5 inch traverses was from the back wall towards the front wall when viewed from the side containing digital thermometers and the data recorded for 0.5 inch traverses was from the right wall towards the left wall (see Fig. 3.3). Section 4.1 presents the results for the downflow of the liquid that resulted from the 2.2 degrees clockwise tilt of the thermosiphon. Section 4.2 presents the results for the upflow of the liquid that resulted due to 2.1 degrees counterclockwise tilt of thermosiphon. Section 4.3 presents the results for zero degree tilt of the thermosiphon, which caused the flow to move upward. Section 4.4 presents results for a study of maximum thermosiphon velocity versus tilt angle.

\section{Section 4.1: Results for downflow of the liquid}

In the present study downflow of the liquid in the test section has been considered as negative velocity and the upflow has been considered as positive velocities. Counterclockwise tilt of the thermosiphon when viewed from the side containing the Swagelok fittings and temperature probes (Fig. 3.2a or Fig. 2.1) resulted in upflow in the test section, while clockwise tilt resulted in the downflow through the test section. The average velocity profiles for the 1.5 inch traverse, 0.5 inch traverse (Center), 0.5 inch traverse (Right end) are shown for two downflow runs in Figs. 4.1.1- 4.2.5. The data has been plotted versus dimensionless distance $\mathrm{x} / \mathrm{H}$ for the 1.5 inch traverse and versus dimensionless distance $\mathrm{y} / \mathrm{W}$ for the 0.5 inch traverses. For the 1.5 inch traverse, velocity 
measurements were made for increments in the $\mathrm{x}$ direction of $1 / 16$ th of an inch $(\Delta \mathrm{x} / \mathrm{H}=0.05)$. For the 0.5 inch traverses, velocity measurements were made for increments in the $y$ direction of $1 / 32$ nd of an inch $(\Delta y / W=0.0625)$.

No velocities were measured for $\mathrm{x}>1.2$ inches for the 1.5 inch traverse and $\mathrm{y}>$ 0.32 inches for the 0.5 inch traverse because the PMT output voltage signal was observed to become very noisy or become saturated as the LDV probe volume approached the test section walls. Then it was presumed that no reliable velocity data could be obtained very close to either the right, left, far or near wall. This low signal quality is expected to have been due to the reflections or backscatter of laser light ("flare") from the test section walls.

It was observed that the number of Doppler bursts or the data rate was reduced gradually after the system reached the steady state and had operated for some time. The reason for this was that the seeded particles, consisting of the microbaloons and the eroded aluminium particles from the inner face of the pipe loop, tended to break apart over time or possibly to collect somehow at the corners, thereby reducing the seeding density and number of Doppler bursts. The signal to noise ratio also gradually became lower as the probe volume was traversed near the walls due to the laser light reflecting from the test section walls, or due to the presence of small air bubbles on the inner wall of the pipe loop and a thin film of coating possibly due to erosion of aluminum from the inner face of the loop that built up gradually over time. 
Figs. 4.1.1 through 4.1.3 and 4.2.1 through 4.2.3 present LDV mean and RMS velocity data versus the dimensionless distance $(\mathrm{x} / \mathrm{H}$ for 1.5 inch traverse and $\mathrm{y} / \mathrm{W}$ for 0.5 inch traverse) for two runs with the downflow of the liquid and the experimental setup tilted 2.2 degrees clockwise. For the 1.5 inch traverse velocities were no more than 2 $\mathrm{cm} / \mathrm{s}$ for both the runs. The velocity of the liquid was consistently larger at the back wall and tended to decrease away from the back wall and was least near the front wall. The RMS velocities varied from $0.15-0.3 \mathrm{~cm} / \mathrm{s}$ for the first run and $0.17-0.38 \mathrm{~cm} / \mathrm{s}$ for the second run. The turbulence intensities (defined as the ratio of the measured RMS velocity divided by the mean velocity) ranged between $10-20 \%$ for both the runs. It is believed that individual data points where higher RMS velocities were measured than for neighboring data points $(3 \mathrm{~mm} / \mathrm{s}$, versus 2 to $2.5 \mathrm{~mm} / \mathrm{s}$ ) may have been due to a greater level of noise in the Doppler signals at those points, either due to an air bubble or dirt on the test section walls at that location, or due to an increase in the amount of laser light scattered off of the test section walls.

Figs. 4.1.2 and 4.2.2 present the LDV velocity data for the 0.5 inch traverse at the center of the 1.5 inch side of the test section for the two downflow runs. The traverse was from the right wall towards the left wall. The average velocities were no more than 1.75 $\mathrm{cm} / \mathrm{s}$. These values were consistent with mean values for 1.5 inch traverse directions. The RMS velocities were between $0.1-0.3 \mathrm{~cm} / \mathrm{s}$ for both the runs. The turbulence intensity was $10-25 \%$ for both the runs. 
Figs. 4.1.3 and 4.2.3 presents the velocity data for the 0.5 inch traverse at the back end of the 1.5 inch side of the test section. The average velocities tend to increase from the right wall towards the left wall. Average velocities were no more than $1.75 \mathrm{~cm} / \mathrm{s}$ for the first run and no more than $2.25 \mathrm{~cm} / \mathrm{s}$ for the second run. The RMS velocities were between $0.1-0.3 \mathrm{~cm} / \mathrm{s}$ for both the runs. The turbulence intensity was between $10-20 \%$ for both the runs.

Figs. 4.1.4 and 4.2.4 present several examples of the data series for runs 1 and 2 of the LDV data for the two runs for different traverses at locations indicated in the figures. The flow direction was down and the experimental setup was tilted $2.2 \mathrm{deg}$ clockwise for both the runs. Clearly it is not a steady flow; perhaps oscillations are due to vortices shed due to corners or vortices shed off of the temperature probes, or unsteadiness due to mixing between different temperature liquid from the flow channel walls and centerline. The computed Reynolds number is 365 for an order-of-magnitude velocity of $2 \mathrm{~cm} / \mathrm{s}$, dynamic viscosity $\mu=0.0004963 \mathrm{~kg} / \mathrm{m}-\mathrm{s}$, and the hydraulic radius of $0.453 \mathrm{~cm}$. Since the Reynolds number was less than 1000 it was judged that the flow should be laminar, so the observed variations are not believed to be due to what would traditionally be called turbulence. The Grashoff number calculated (based on White, Heat and Mass Transfer, 1988) was 208,200 (temperature difference considered here is the temperature difference at the heaters). For a vertical flat plate by assuming the local Grashoff number to be $10^{9}$ (based on White, Heat and Mass Transfer, 1988) the transition to turbulence would occur at an $\mathrm{x}$ distance of $12.76 \mathrm{~m}$ (temperature difference considered here is the difference between wall temperature and the local temperature). However 
there is large scale unsteadiness due to secondary flow (passage vortices) and buoyancy driven mixing of cooler water near top and bottom walls of top leg thermosiphon with hotter water from center of flow passage in vertical leg of thermosiphon. The data series shown are not true time series, because the time between individual LDV data points was a random variable, and was not recorded in present work, due to equipment limitations. Thus spectra and correlation coefficients could not be computed.

Fig. 4.2.5 shows the variation of temperature with respect to time for different traverses for the second run. Temperatures were not recorded for run $\# 1$, but the maximum temperature was again nominally 50 degrees Celsius for this run and was observed to be nearly constant. Variation of temperatures at the four corners of the test loop are plotted versus time where $T_{1}$ is the bottom left corner, $T_{2}$ is the bottom right, $T_{3}$ is the top right and $\mathrm{T}_{4}$ is the top left corner (see Figs. 2.1 and 3.2a). All temperatures have been measured with the help of digital thermometers. $T_{\text {air }}$ is the room temperature. From this figure it was judged that the present LDV data was acquired at steady state thermal operating conditions of the thermosiphon.

The average heat transfer rate from the thermoelectric heaters to the water was 51 watts for run number two, and from water to the thermoelectric coolers the cooling rate was 27 watts. The heat transfer efficiency of the coolers was about $54 \%$ as that of the heaters. The average expected velocity is based on the equation (Gray, 2000) $\mathrm{V}=\alpha_{\mathrm{s}}{ }^{2}{ }^{2}{ }^{*} \mathrm{~L}_{2} * \Delta \mathrm{T} *\left(\mathrm{~g}+\mathrm{g}_{\mathrm{E}}\right) / 16^{*} \gamma_{\mathrm{s}} *\left(\mathrm{~L}_{1}+\mathrm{L}_{2}\right)$.....(Equation 4.1) where $\alpha_{\mathrm{s}}=$ coefficient of thermal expansion at reference temperature $T_{\mathrm{s}}$ 
$\mathrm{r}=$ pipe radius

$\Delta \mathrm{T}=$ maximum temperature excess

$\mathrm{L}_{1}=$ length of heated and cooled horizontal legs

$\mathrm{L}_{2}=$ length of insulated vertical legs

$\mathrm{g}=$ gravitational force per mass

$\mathrm{g}_{\mathrm{E}}=$ effective gravitational force per mass due to Kelvin force; zero in this work $\gamma_{\mathrm{s}}=$ kinematic viscosity at reference temperature $T_{\mathrm{s}}$.

For the second run the expected velocity was $7.59 \mathrm{~cm} / \mathrm{s}$ as compared to the value of 1.8 $\mathrm{cm} / \mathrm{s}$ that was observed. The heat loss from the flow loop was reduced as much as possible by insulating the flow loop using Styrofoam.

The mean velocity for runs 1 and 2 was approximately on the order of $-2 \mathrm{~cm} / \mathrm{s}$, RMS velocity was approximately in the order of $1-3 \mathrm{~mm} / \mathrm{s}$ and turbulence intensity was in the order of $10-20 \%$ for both downflow runs.

\section{Section 4.2:Results for the upflow of the liquid}

For the runs that had upward flow of the liquid, measurements were made that were similar for the downflow runs. The flow was made to go upward by tilting the experimental setup 2.1 degrees counterclockwise when viewed for the side of the thermosiphon containing the temperature probes; see Fig. 3.2a. 
The LDV data for the two upflow runs is shown in Figs. 4.3.1 through 4.3.3 and 4.4.1 through 4.4.3. The data was again plotted versus dimensionless distance $(\mathrm{x} / \mathrm{H}$ for the 1.5 inch traverse and $\mathrm{y} / \mathrm{W}$ for the 0.5 inch traverse). From Figs. 4.3.1 and 4.4.1 it is evident that the velocities across the 1.5 inch traverse were no more than $3 \mathrm{~cm} / \mathrm{s}$ for both runs. Velocity was higher at the back end of the wall and tended to decrease away from the back wall and was least near the front wall. The RMS velocities varied from 0.25 $0.7 \mathrm{~cm} / \mathrm{s}$ for the first run and $0.25-0.55 \mathrm{~cm} / \mathrm{s}$ for the second run. The turbulence intensities varied between 10 - 30\% for both runs. Greater noise levels in the Doppler signals at some points, or an air bubble or dirt on the test section walls, could account for higher RMS velocities at some individual data points than for neighboring data points (6 $\mathrm{mm} / \mathrm{s}$, versus $3-3.5 \mathrm{~mm} / \mathrm{s})$.

The LDV velocity data for the 0.5 inch traverse at the center is shown in Figs. 4.3.2 and 4.4.2 for the two upflow runs. The traverse was from the right wall towards the left wall. The average velocities were no more than $2.2 \mathrm{~cm} / \mathrm{s}$ for the first run and no more than $1.8 \mathrm{~cm} / \mathrm{s}$ for the second run. RMS velocities ranged between $0.4-0.6 \mathrm{~cm} / \mathrm{s}$ for the first run and $0.3-0.5 \mathrm{~cm} / \mathrm{s}$ for the second run. Turbulence intensities ranged between 20 $-40 \%$ for the first run and $15-35 \%$ for the second run.

The LDV velocity data for the 0.5 inch traverse at the back end of the flow channel is shown in Figs. 4.3.3 and 4.4.3 for the two upflow runs. The traverse was from the right wall towards the left wall. The average velocities were no more than $3 \mathrm{~cm} / \mathrm{s}$ for both the runs. RMS velocities ranged between $0.2-0.4 \mathrm{~cm} / \mathrm{s}$ for both the runs. Turbulence intensities ranged between $10-20 \%$ for both the runs. 
Examples of data series for the two runs for different traverses are shown in Figs. 4.3.4 and 4.4.4. The experimental setup was tilted 2.1 degrees counterclockwise and the flow direction was up. From the figures it is evident that the flow is not steady. The oscillations are perhaps due to the vortices shed from corners. The Reynolds number is 365 for an order-of-magnitude velocity of $2 \mathrm{~cm} / \mathrm{s}$. Since this Reynolds number is less than 1000 it was again judged that the flow was laminar, so turbulence should not play a role in the observed variations.

Figs. 4.3.5 and 4.4.5 show the variation of temperature with respect to time for different traverses for the first and second run for the upflow of the liquid. From the figure it is evident that the LDV data was acquired at steady state thermal operating conditions of the thermosiphon.

The average heat transfer from the thermoelectric heaters was 96 watts and the average heat transfer from the thermoelectric coolers was 32 watts, which is $33 \%$ as that of the heaters. The average predicted velocity was $6.36 \mathrm{~cm} / \mathrm{s}$ based on equation 4.1 as compared to a value of $2.14 \mathrm{~cm} / \mathrm{s}$ that was observed. The average heat transfer from the thermoelectric heaters for the second run was 69 watts and the average heat transfer from the thermoelectric coolers was 19 watts, which was $27 \%$ of the heaters. The predicted velocity for the second run was $6.54 \mathrm{~cm} / \mathrm{s}$ compared to the observed value of $1.9 \mathrm{~cm} / \mathrm{s}$.

\section{Section 4.3: Results for the upflow of the liquid with zero tilt}


Measurements were made with $0 \pm 0.1$ degree tilt of the experimental setup. The flow of the liquid was observed to be in the upward direction for this run. It is believed that the flow could start in either direction at 0 degree tilt.

Fig. 4.5.1 presents the LDV velocity data acquired for zero degree tilt of the experimental setup. The data was plotted in the same way as for previous runs with different angles of tilt. Mean velocities were no more than $2.5 \mathrm{~cm} / \mathrm{s}$. The traverse was from the back wall of the 1.5 inch side towards the front wall. The RMS velocities were between $0.25-0.5 \mathrm{~cm} / \mathrm{s}$, so the turbulence intensity varied between $10-30 \%$.

Fig. 4.5.2 presents example data series for the zero degree tilt of the experimental setup. The flow direction was upward for this run. This figure shows that the flow was definitely not steady; it is believed that the oscillations are perhaps due to vortices shed due to the corners. The computed Reynolds number is 456 for an order of magnitude velocity of $2.5 \mathrm{~cm} / \mathrm{s}$.

Fig. 4.5.3 shows the variation of temperature with respect to time for the 1.5 inch traverse with upward motion of the liquid. From the figure it is judged that the LDV data was acquired at fairly steady state operating conditions of the setup.

The average heat transfer from the thermoelectric heaters was 81 watts and from the thermoelectric coolers was 32 watts, which is $40 \%$ of the heaters. The predicted 
velocity was $7.67 \mathrm{~cm} / \mathrm{s}$; based on the equation 4.1 as compared to the observed value of $2.1 \mathrm{~cm} / \mathrm{s}$.

Velocity data was recorded every 3 minutes over a time period of 30 minutes at the same location on the channel centerline. The thermosiphon was tilted at $0 \pm 0.4$ degrees and the direction of flow observed was upward. The average velocity at the same location did not vary much, and there was no evidence that the flow would ever reverse direction. The overall average velocity was $1.97 \mathrm{~cm} / \mathrm{s}$ upward. The maximum average velocity observed was $2.11 \mathrm{~cm} / \mathrm{s}$ and the minimum average velocity was $1.85 \mathrm{~cm} / \mathrm{s}$. The average RMS velocity was $0.375 \mathrm{~cm} / \mathrm{s}$. The average turbulence intensity was $19.1 \%$. The maximum turbulence intensity was $23.5 \%$ and the minimum turbulence intensity was $14.1 \%$. It was judged that the average velocity was independent of time at steady state operating conditions on the channel centerline. The observed variations in turbulence intensity are thought to be due to variations in signal-to-noise ratio over time.

\section{Section 4.4: Results for various angles of tilt}

This section presents the results for data that was recorded for various angles of tilt. For all angles of tilt data was recorded at the center of the test section. Clockwise tilt of the thermosiphon resulted in downward flow of the liquid and counterclockwise tilt resulted in upward flow. 
Fig. 4.6.1 presents the LDV mean and RMS velocity data versus angle of tilt at the center of 1.5 inch side of the test section. From the figure it was judged that the angle of tilt has very little or no effect on the mean velocity. The average velocities were no more than $2 \mathrm{~cm} / \mathrm{s}$. The turbulence intensities varied between 10-20\% for different angles of tilt, with consistently larger RMS values and turbulence intensities resulting for positive (ccw) tilt angles. This is believed to be due to a consistently poorer signal-tonoise ratio for positive tilt angles. 


\section{Chapter 5: DISCUSSION, CONCLUSIONS AND RECOMMENDATIONS}

\section{Section 5.1: Discussion}

The experimental results that have been obtained can be compared to the predictions of one dimensional theory. The predicted velocities are 3-4 times bigger than that of observed mean velocities. The reason could be that the one dimensional model (D. D. Gray, personal communication, 2001) (equation 4.1) assumes a steady laminar flow without minor losses or axial conduction, but there could be heat loss from all the legs of the thermosiphon which may be significant.

The mean velocity profiles across the 1.5 inch dimension of the flow area were consistently higher near the back wall and lower near the front wall of the test section. The reason for the higher velocities at the back wall may be due to blockage by the digital thermometer probes on the front half of the test section wall slowing down the flow.

For tilt angles less than the critical angle (angle at which an anti-natural flow changes direction suddenly to adopt a natural flow direction) the velocity does not change significantly with tilt angle. Specifically the present velocity versus tilt angle results (Fig. 4.6.1a) can be compared with similar data in Fig. 5c in Acosta, Sen and Ramos (1987), where at a heat transfer rate of 83 Watts, they observed flow velocities of approximately $2 \mathrm{~cm} / \mathrm{sec}$. For the present work, the average heating rate was 70 Watts.

\section{Error Analysis}

An error analysis was performed for the velocity, temperature and heat transfer measurements. For the velocity measurements the observed non repeatability was calculated to be $21.3 \%$ and $\mathrm{V}=1.80 \pm 0.39 \mathrm{~cm} / \mathrm{s}$. The non repeatability for $\Delta \mathrm{T}_{\mathrm{h}}$ was 24.5 $\%$ and $\Delta \mathrm{T}_{\mathrm{h}}=2.31 \pm 0.57 \mathrm{Deg} \mathrm{C}$. The non repeatability for $\Delta \mathrm{T}_{\mathrm{c}}$ was $17.5 \%$ and $\Delta \mathrm{T}_{\mathrm{c}}=0.88$ 
\pm 0.15 Deg C. The non repeatabilty for $Q_{\text {heating was }} 32.4 \%$ and $Q_{\text {heating }}=70.2 \pm 22.8$ Watts and the non repeatability for $\mathrm{Q}_{\text {cooling }}$ was $25.3 \%$ and $\mathrm{Q}_{\text {cooling }}=26.6 \pm 6.74$ Watts.

\section{Section 5.2: Conclusions}

An experimental laboratory model rectangular loop thermospihon was designed and built such that a complete set of axial velocity measurements could be made using a single-component Laser Doppler Velocimeter. The rectangular loop thermosiphon contained a clear test section, for optical access, which was rectangular in cross section. The pipe loop was filled with distilled water using a funnel and a valve. The setup was operated at steady state operating conditions at a nominal water temperature of 50 degrees $\mathrm{C}$ for all experimental results reported. The experimental facility was designed such that the thermosiphon could be tilted at different angles and that velocity measurements could be made using Laser Doppler Velocimetry, while water temperatures were recorded at each of the four corners of the thermosiphon.

Instantaneous velocity measurements were obtained for different runs for both clockwise and anticlockwise tilt of the thermosiphon. These instantaneous measurements were then used to compute the mean, root-mean-square velocities, and turbulence intensities for both the 1.5 inch and 0.75 inch sides. Results were then plotted versus dimensionless distance across the test section flow area.

The mean velocities at the back wall were consistently higher and gradually decreased towards the front wall for the 1.5 inch dimension of the test section flow area. The mean velocities were negative (downwards) for the clockwise tilt of the thermosiphon for both 1.5 inch and 0.75 inch traverses and were positive (upwards) for counterclockwise tilt of the thermosiphon. For the 1.5 inch traverse the mean velocities 
were higher at the back wall compared to the front wall for both clockwise and counterclockwise tilt of the thermosiphon. The predicted velocities are 3-4 times bigger than the observed mean velocities for the different runs.

The predicted velocities based on equation 4.1 for various angles of tilt were $2.5-3$ times bigger than the observed mean velocities. The observed velocities are in the same order of magnitude as that of the velocities observed by Acosta, Sen and Ramos, (1987) for a heat input of 83 Watts. The data clearly indicates that the angle of tilt has very little or no effect on the mean velocity and turbulence intensity (Fig. 4.6.1a,b).

RMS velocities are in the same order for different angles of tilt. The heat transfer efficiency of the thermoelectric heaters was more than that of the coolers for most of the runs and was in the order of 1.5-2:1. The average value of $Q_{\text {heater }}$ was 74.2 Watts and the average value of $\mathrm{Q}_{\text {cooler }}$ was 27.5 Watts. The Reynolds number, which was below 1000 for all the runs, indicated that the flow was expected to always be laminar and never turbulent.

\section{Section 5.3: Recommendations}

It would be possible to convert this thermosiphon to a magnetothermosiphon by adding a magnet and replacing the distilled water with a paramagnetic fluid, such as manganese chloride in water. Then the pipe loop would be operated in its tilted or horizontal configuration, so that gravity would be perpendicular to the flow direction.

The quality of the data could be improved by coating the inner walls of the Plexiglas test section with some kind of antireflective material, and using optical quality glass for the test section walls. This would significantly increase the LDV data signal-to 
noise ratio caused by the interference of the beams with the test section walls. The temperature instrumentation could be automated by replacing the digital thermometers with either RTD's or thermocouples and recording the temperatures using a data acquisition board and a computer. The aluminium pipe loop could be coated with some form of anticorrosive material to avoid corrosion and prevent the corroded particles from entering the flow. Finally, the setup could be placed in a temperature-controlled laboratory to minimize the effects of room temperature variation. Also, PIV could be used to study velocity time histories in a plane to see if the observed flow unsteadiness is due to vortex shedding from corners. 


\section{References}

R. Acosta, M. Sen and E. Ramos, "Single-phase natural circulation in a tilted square loop," Warme-und Stoffubertragung, 21, Springer-Verlag 1987, pp. 269-275

J. R. Carruthers and R. Wolfe, "Magnetothermal Convection in Insulating Paramagnetic Fluids,” Journal of Applied Physics. 39, 1968, pp. 5718-5722

H. Cohen and F. J. Bayley, "Heat-transfer Problems of Liquid-cooled Gas-turbine Blades," Proc. Inst. Mech. Eng. (London) 169(53), 1955, pp. 1063-1074

P. S. Damerrell and R. J. Schoenals, "Flow in a Toroidal Thermosyphon with Angular Displacement of the Heated and Cooled Sections," J. Heat Transfer, Vol. 101, 1979, pp. 672-676

T. H. Davies and W. D. Morris, Ind. Eng. Dig. 29(11/12), 1965, pp. 87-91

F. Durst, A. Melling, J. H. Whitelaw, Principles and Practice of Laser Doppler Anemometry, Second Edition, Academic Press, London, 1981

D. D. Gray, J. Huang and B. F. Edwards, "Effective Gravity in Magnetothermal Convection," Proceedings of the $12^{\text {th }}$ Engineering Mechanics Conference, La Jolla, California, 1998, pp. 1661-1664

I. E. Idelchik, Handbook of Hydraulic Resistance, Second Edition, 1986

D. Japikse, "Advances in Thermosyphon Technology," Advances in Heat Transfer, 9, T. F. Irvine, Jr., and J. P. Hartnett, eds, Academic Press, 1973

A. Mertol and R. Greif, "A Review of Natural Circulation Loops," Hemisphere Publishing Corporation, 1985, pp. 1033-1071

T. A. Nyce and F. Rosenberger, "A General Method For Calculating Natural Convection Flows In Closed Loops,” Chem. Eng. Comm., 1995, Vol. 134, pp. 147155

J. A. Roberson and C. T. Crowe, Engineering Fluid Mechanics, Houghton Mifflin Company, 1985 1985

R. E. Rosensweig, Ferrohydrodynamics, Cambridge University Press, New York,

E. Schmidt, "Heat Transmission by Natural Convection at High Centrifugal Acceleration in water-cooled Gas-turbine Blades," Proc. Inst. Mech. Eng. A.S.M.E (London) Conf. Proc. 1951, pp. 361-363

TSI Incorporated, "Laser Velocimetry Systems," catalog, St. Paul, MN

F. M. White, Heat and Mass Transfer, Addison-Wesley Publishing Company, 1988, pp. 395-401 


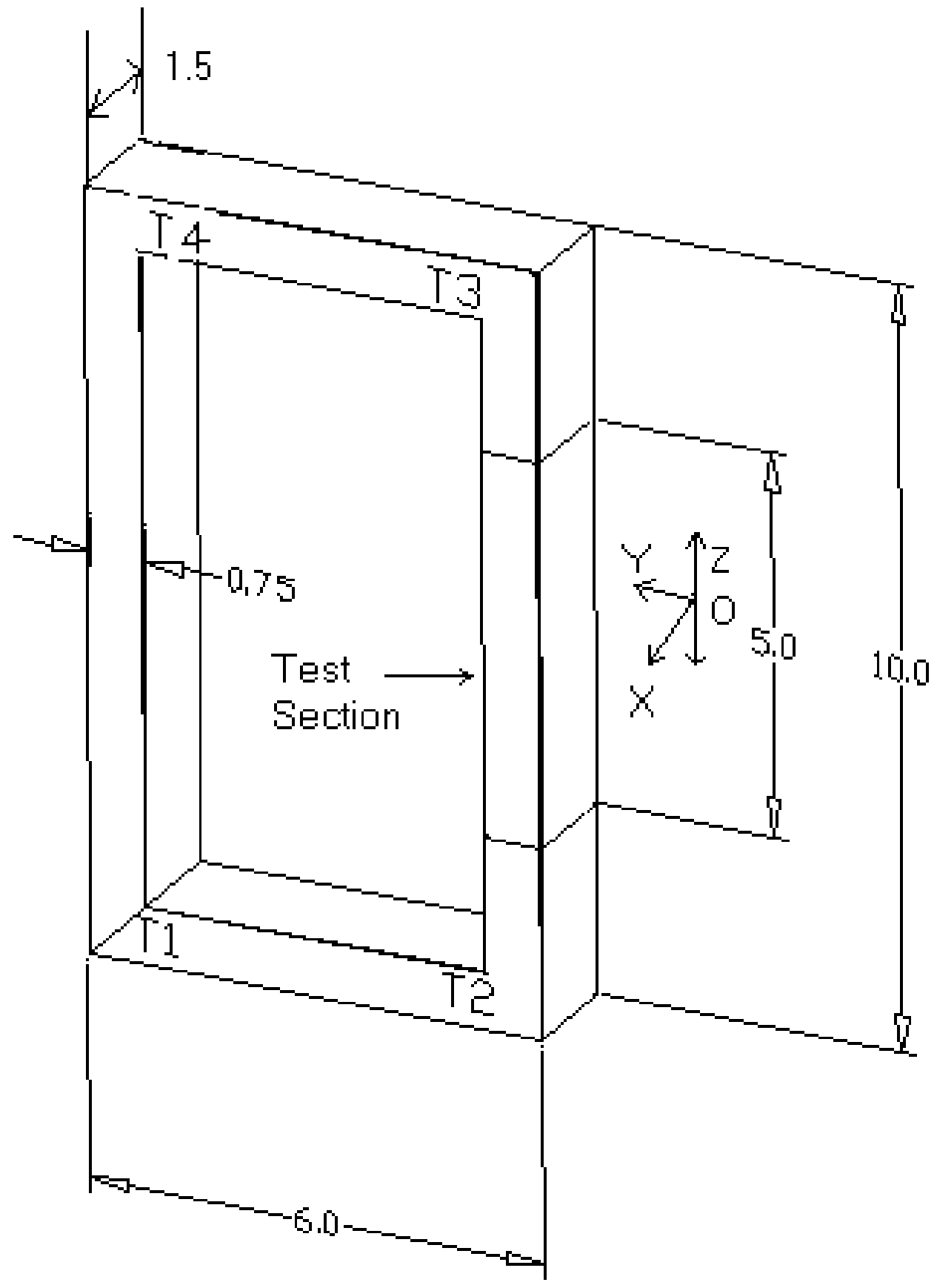

Fig 2.1 Closed loop thermosiphon 


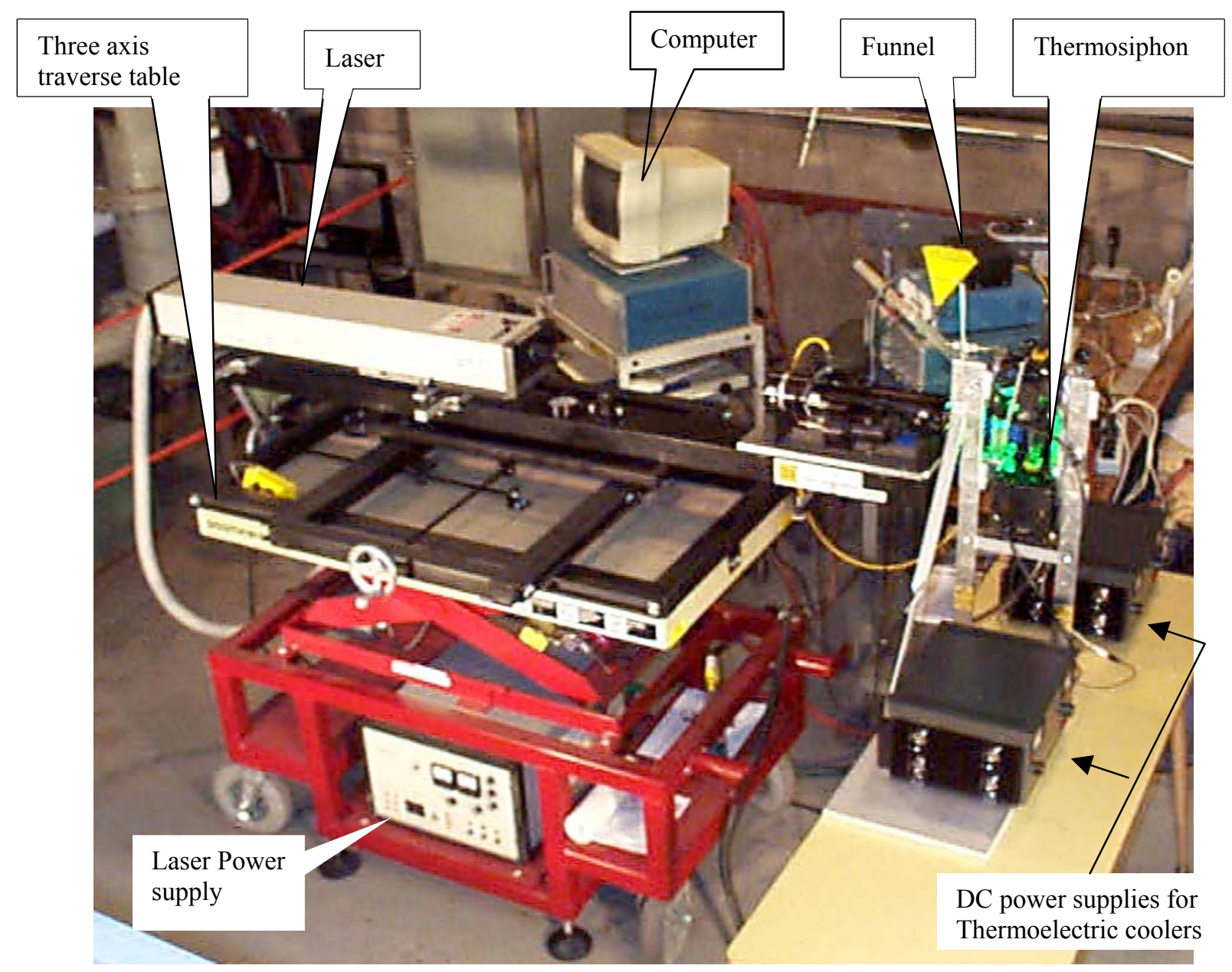

Fig. 3.1 Overview of thermosiphon, LDV system and traverse table 


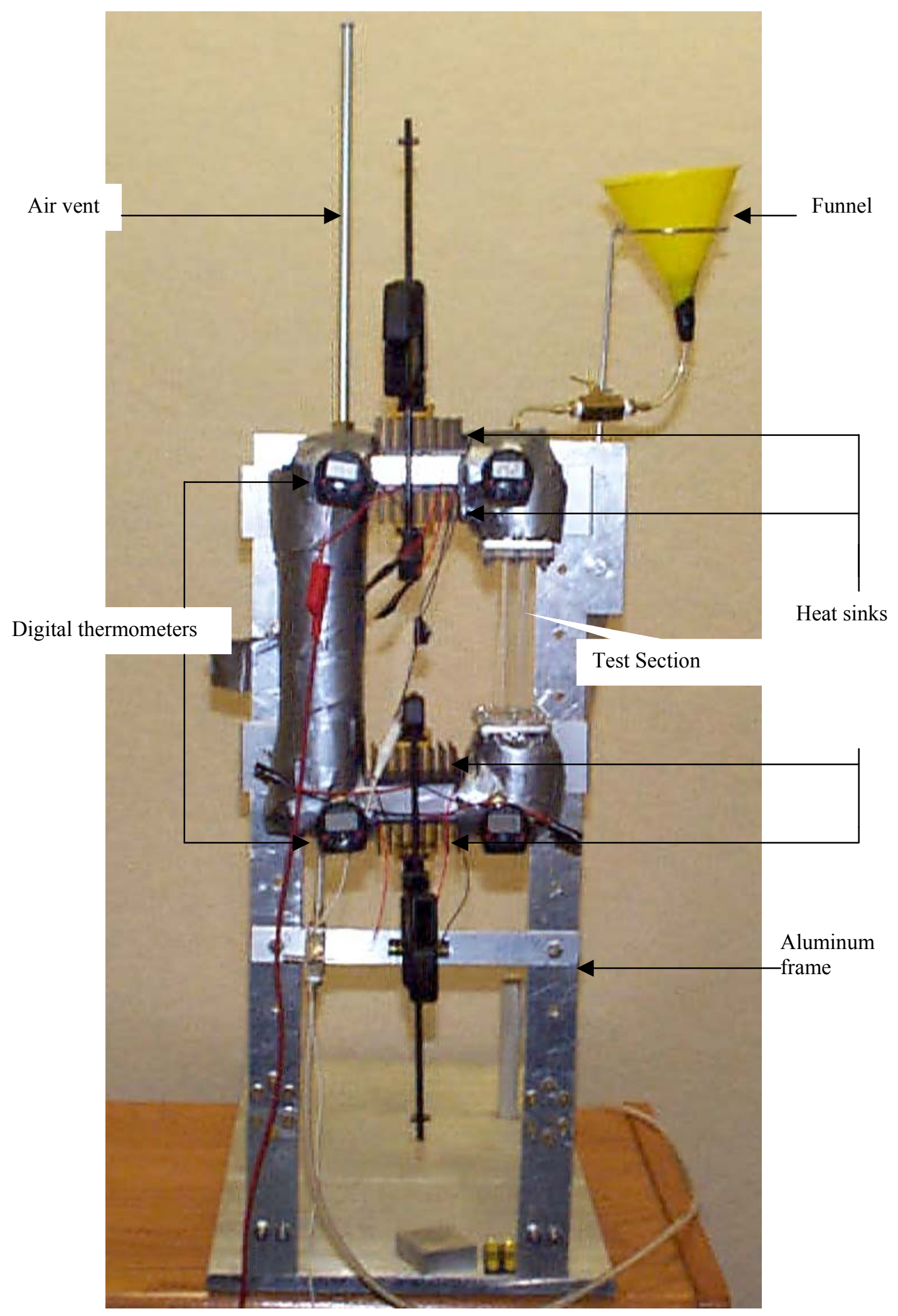

Fig. 3.2a Front view of the thermosiphon mounted on aluminum frame 


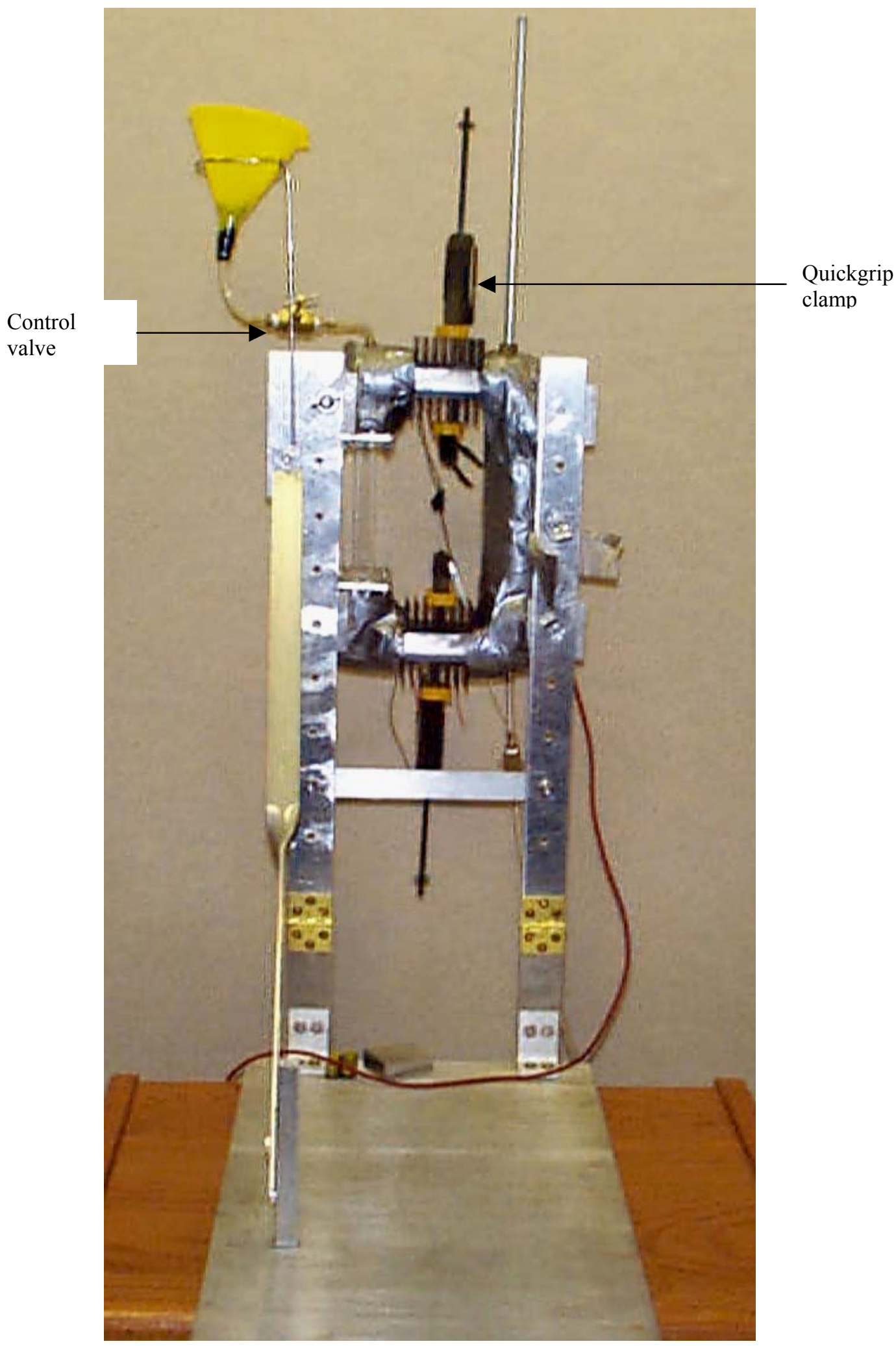

Fig. 3.2b Rear view of the thermosiphon with aluminum frame 


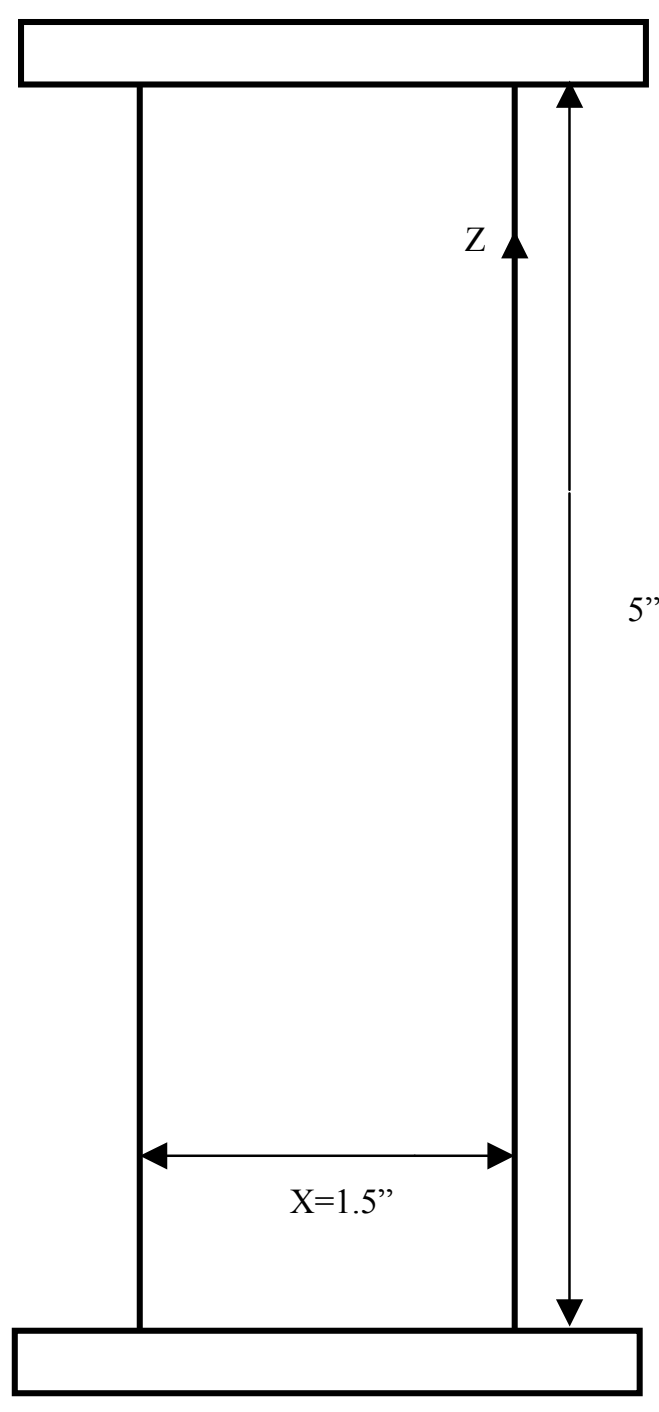

A)

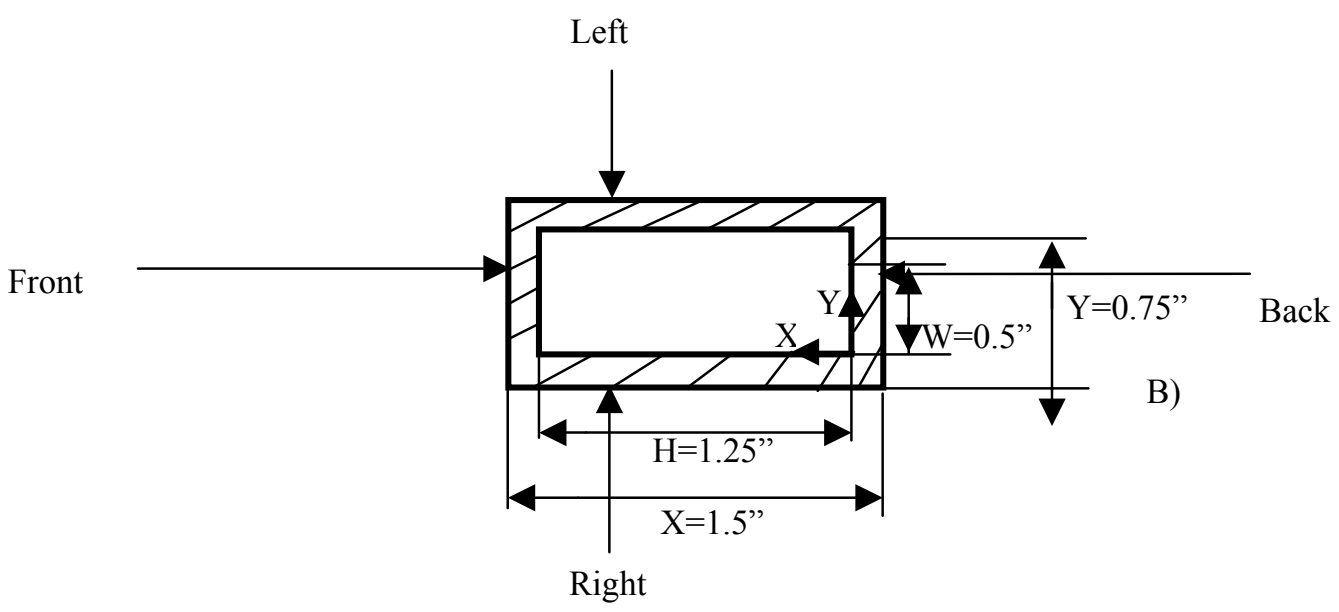

Fig 3.3 Line drawing of the test section

A) End view B) Top view 


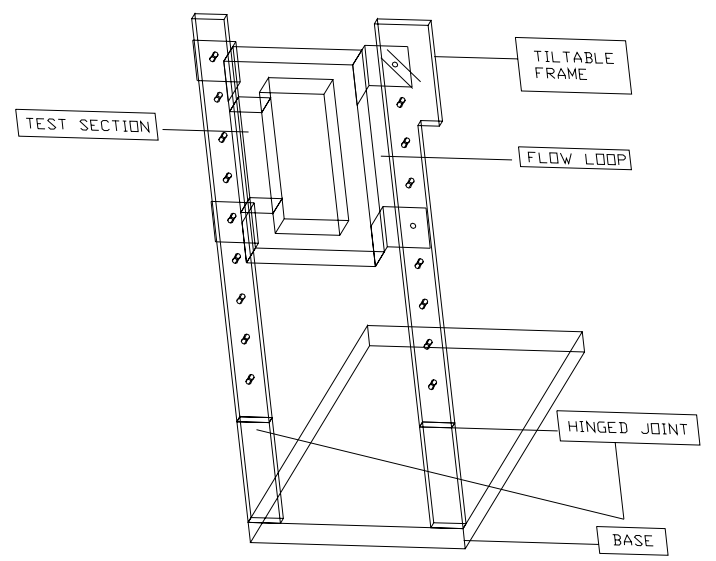

A

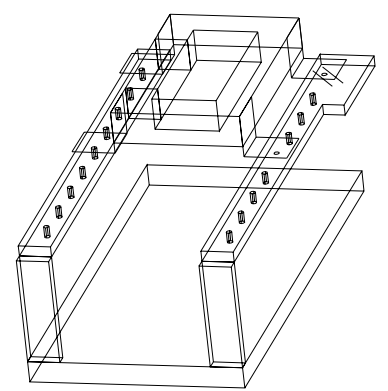

B

Fig. 3.4 AutoCAD drawing of the thermosiphon A) Vertical B) Tilted 


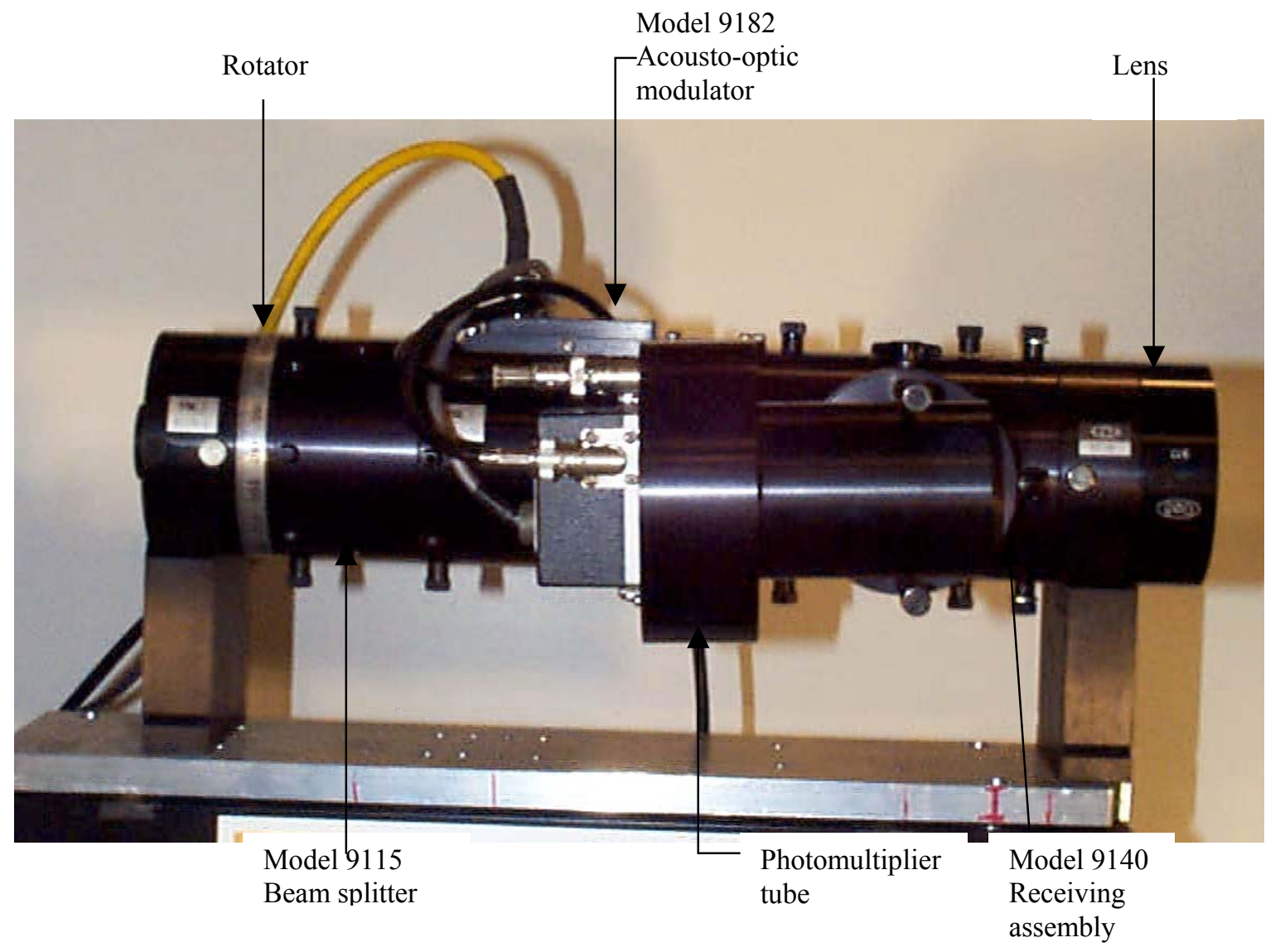

Fig 3.5 LDV optics 


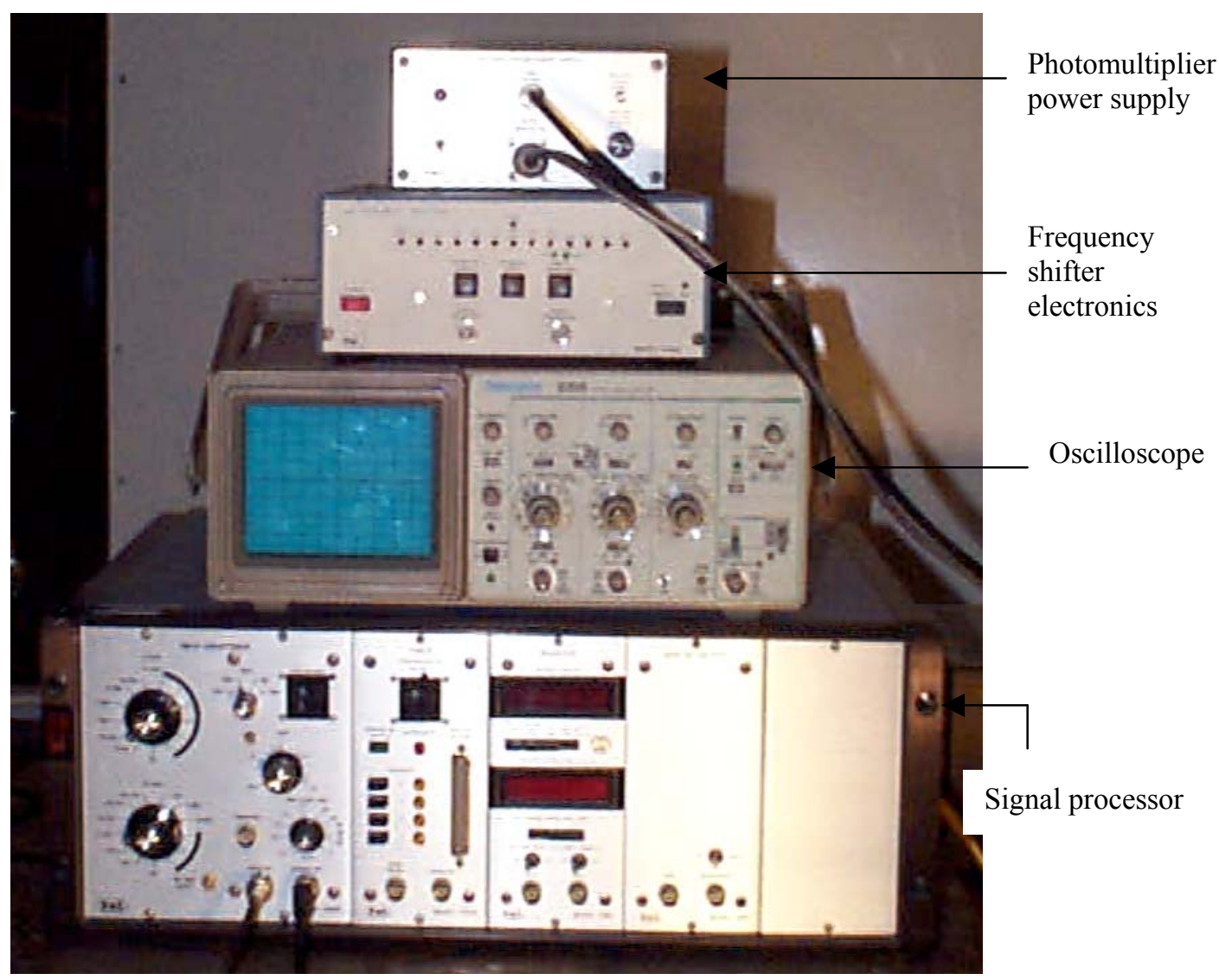

Fig. 3.6 LDV electronics 

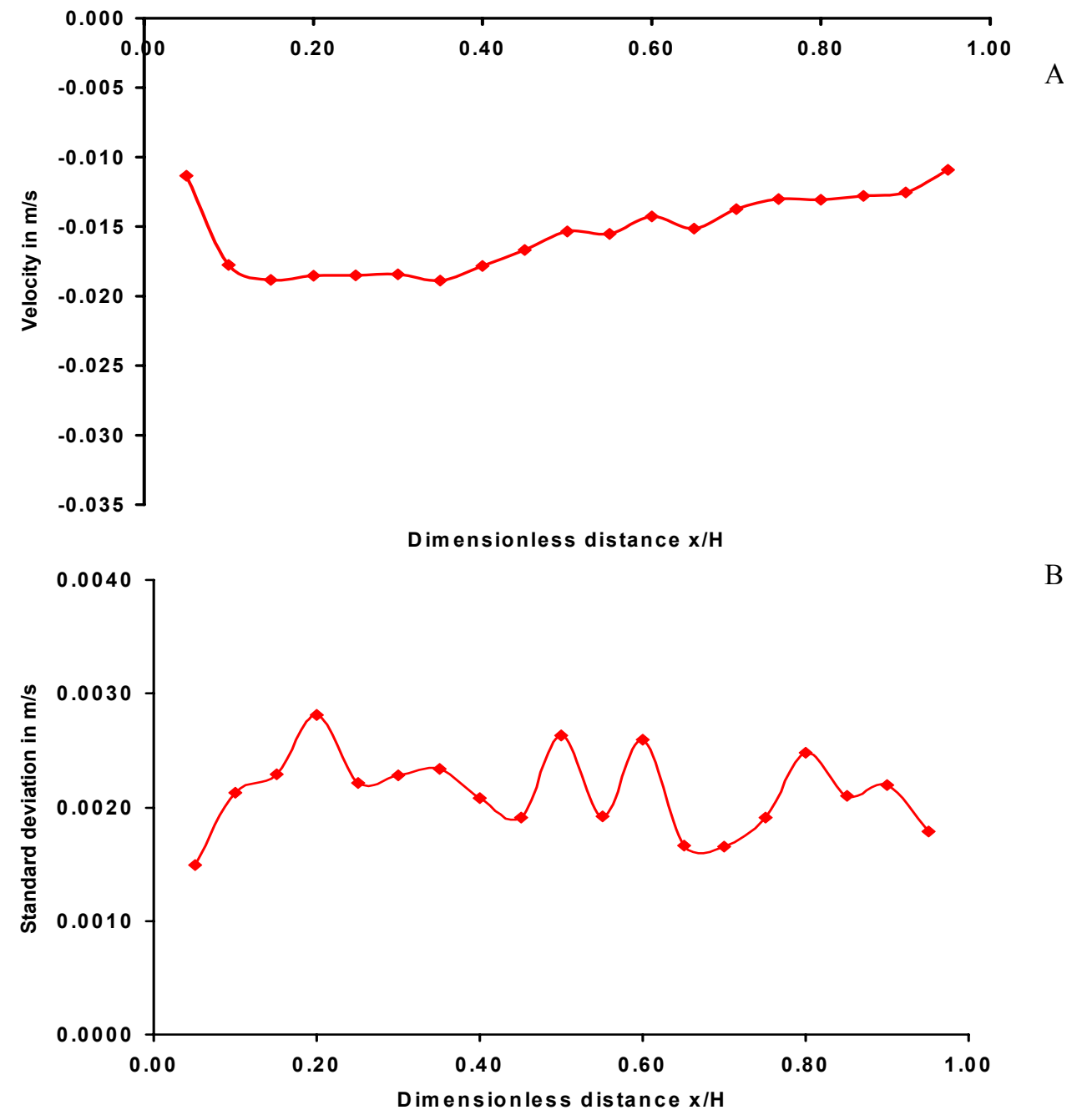

B

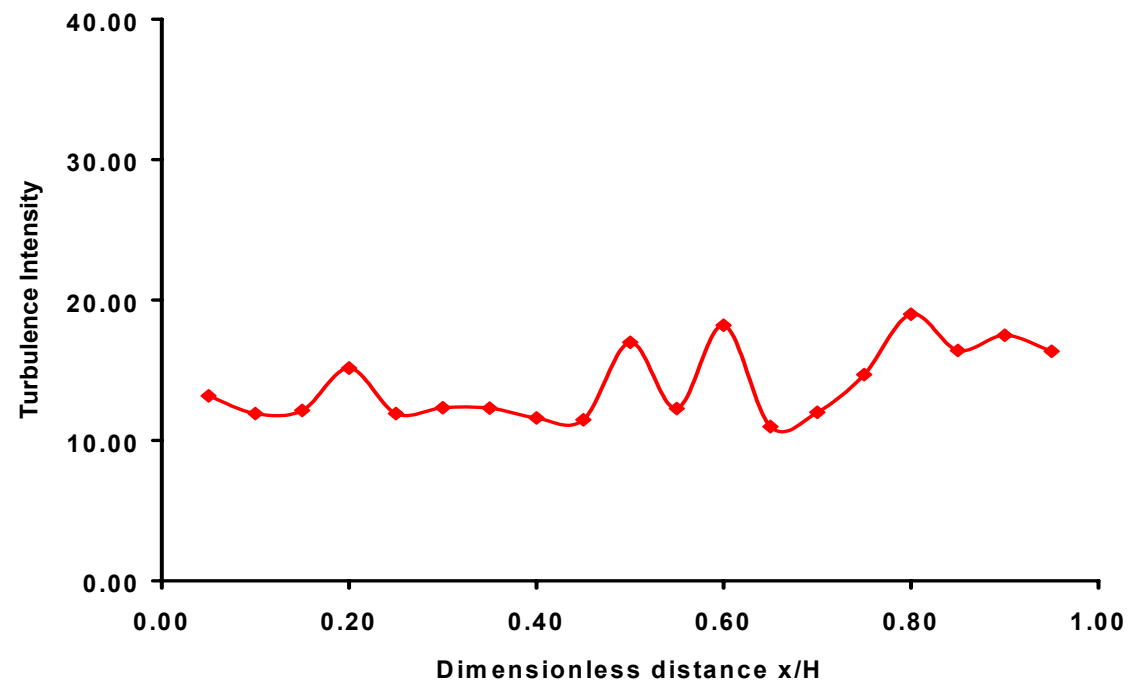

$\mathrm{C}$

Fig. 4.1.1 LDV velocity data versus dimensionless distance for 1.5 inch traverse (Run \# 1; downflow; 2.2 deg ccw tilt )

A) Mean velocity B) Standard deviation C) Turbulence Intensity 

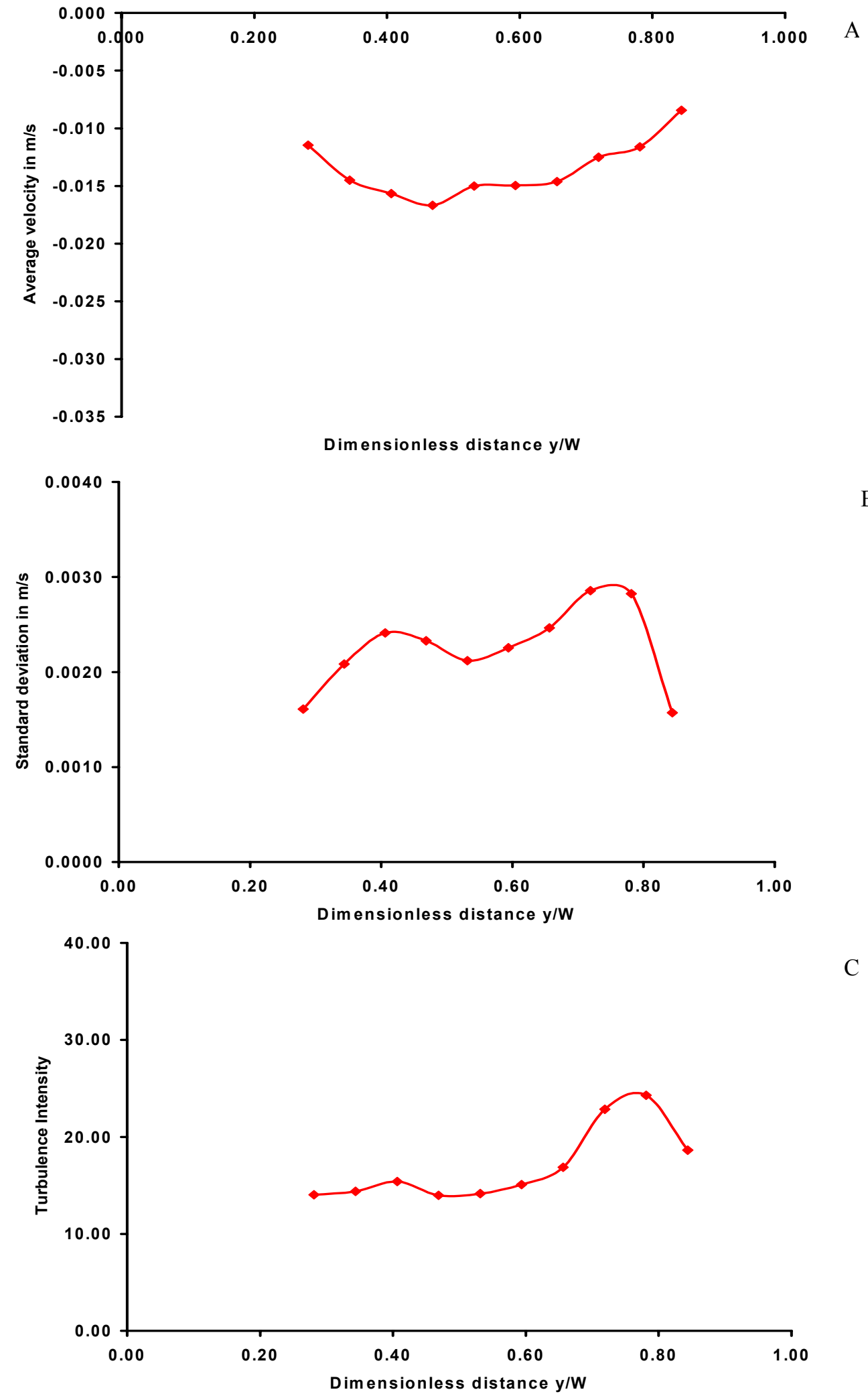

Fig. 4.1.2 LDV velocity data versus dimensionless distance for 0.5 inch traverse (Center) (Run \# 1; downflow; 2.2 deg ccw tilt )

A) Velocity B) Standard deviation C) Turbulence Intensity 

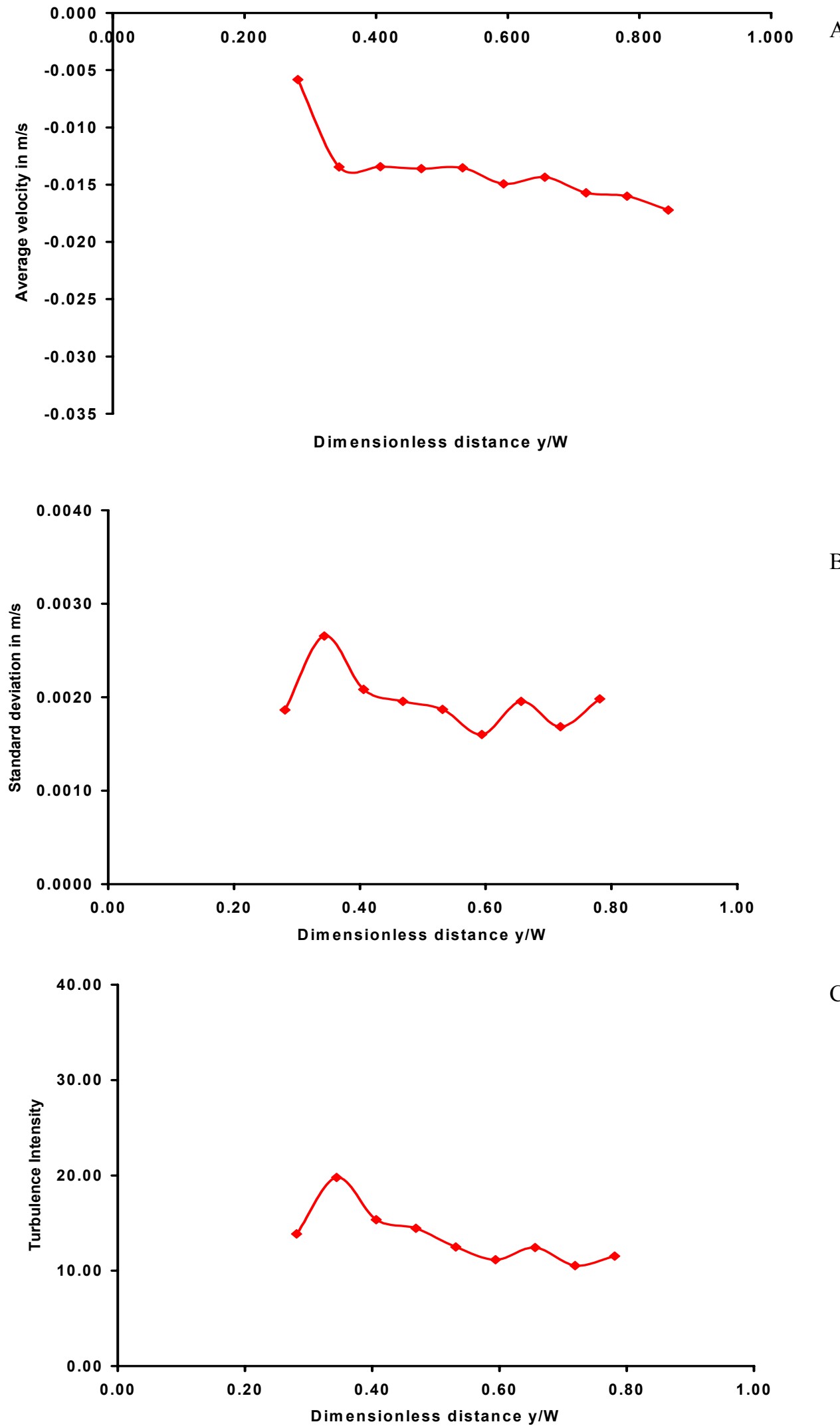

Fig. 4.1.3 LDV velocity data versus dimensionless distance for 0.5 inch traverse (Back end) (Run \# 1; downflow; 2.2 deg ccw tilt )

A) Mean velocity B) Standard deviation C) Turbulence Intensity 

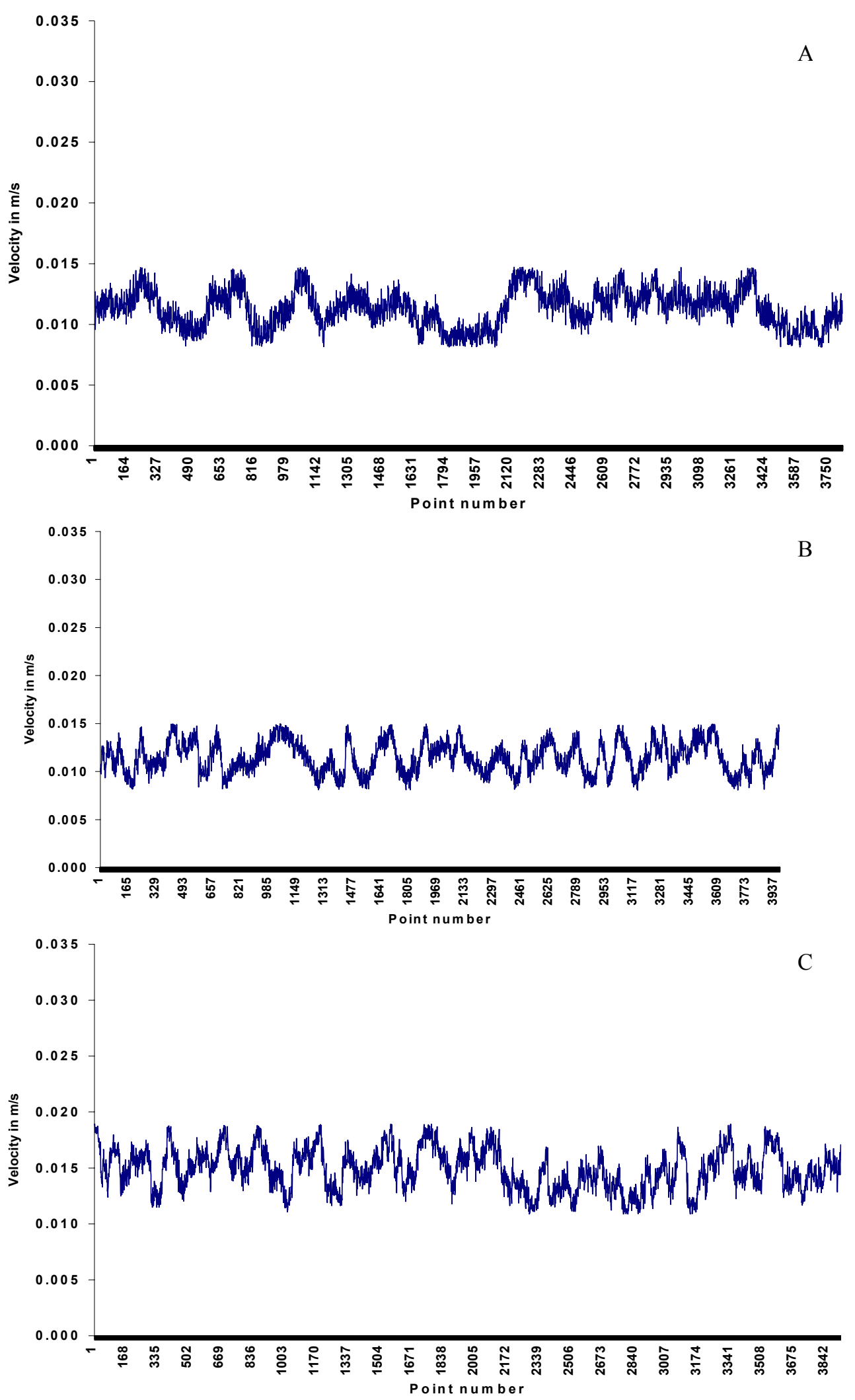

Fig. 4.1.4 LDV data series for the different traverses (Run \#1; downflow; 2.2 deg ccw tilt) A) 1.5 inch traverse B) 0.5 inch traverse (Center) C) 0.5 inch traverse (Back end) 

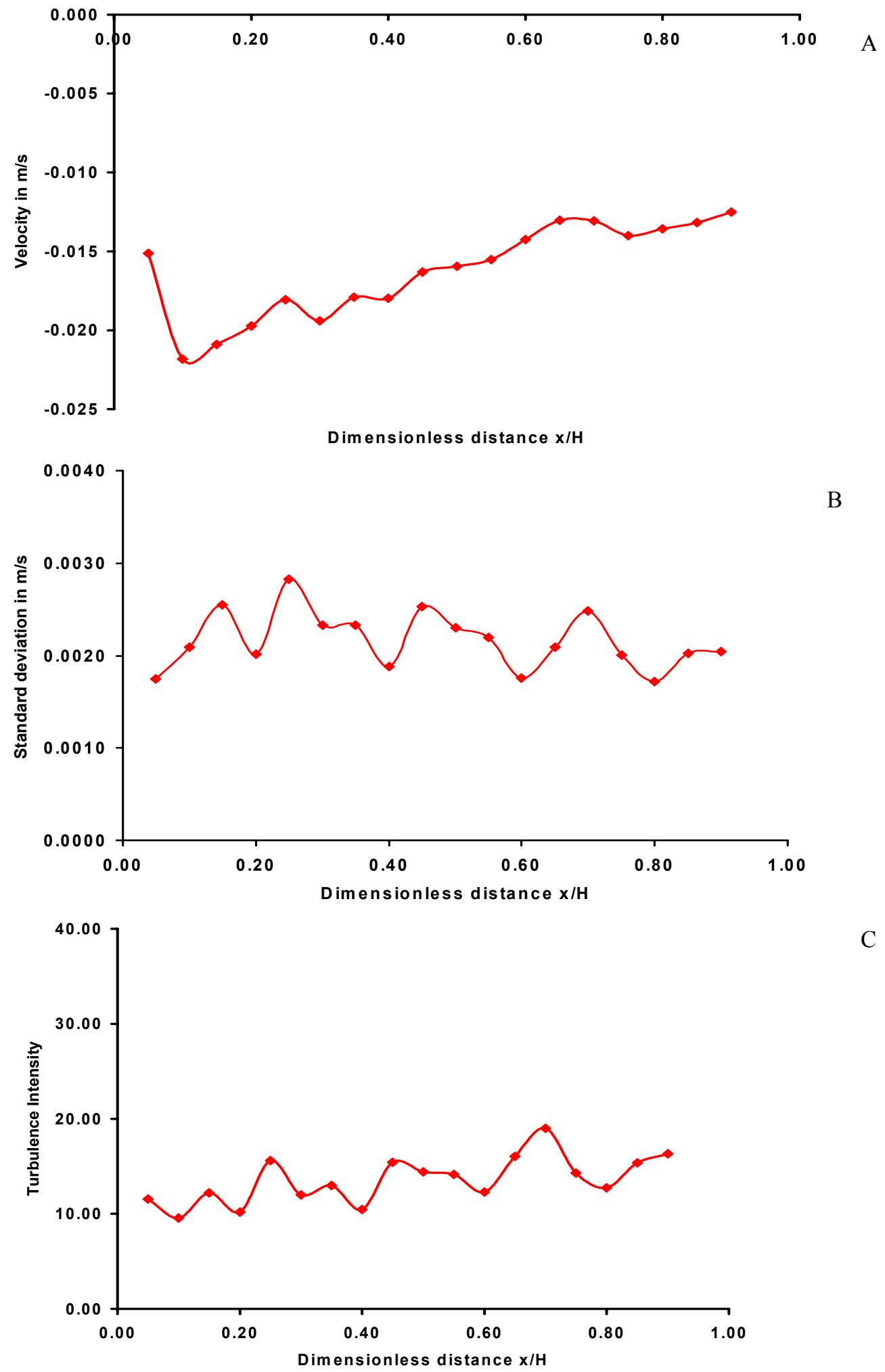

Fig. 4.2.1 LDV velocity data versus dimensionless distance for 1.5 inch traverse (Run \# 2; downflow; 2.2 deg cw tilt )
A) Mean velocity B) Standard deviation C) Turbulence Intensity 

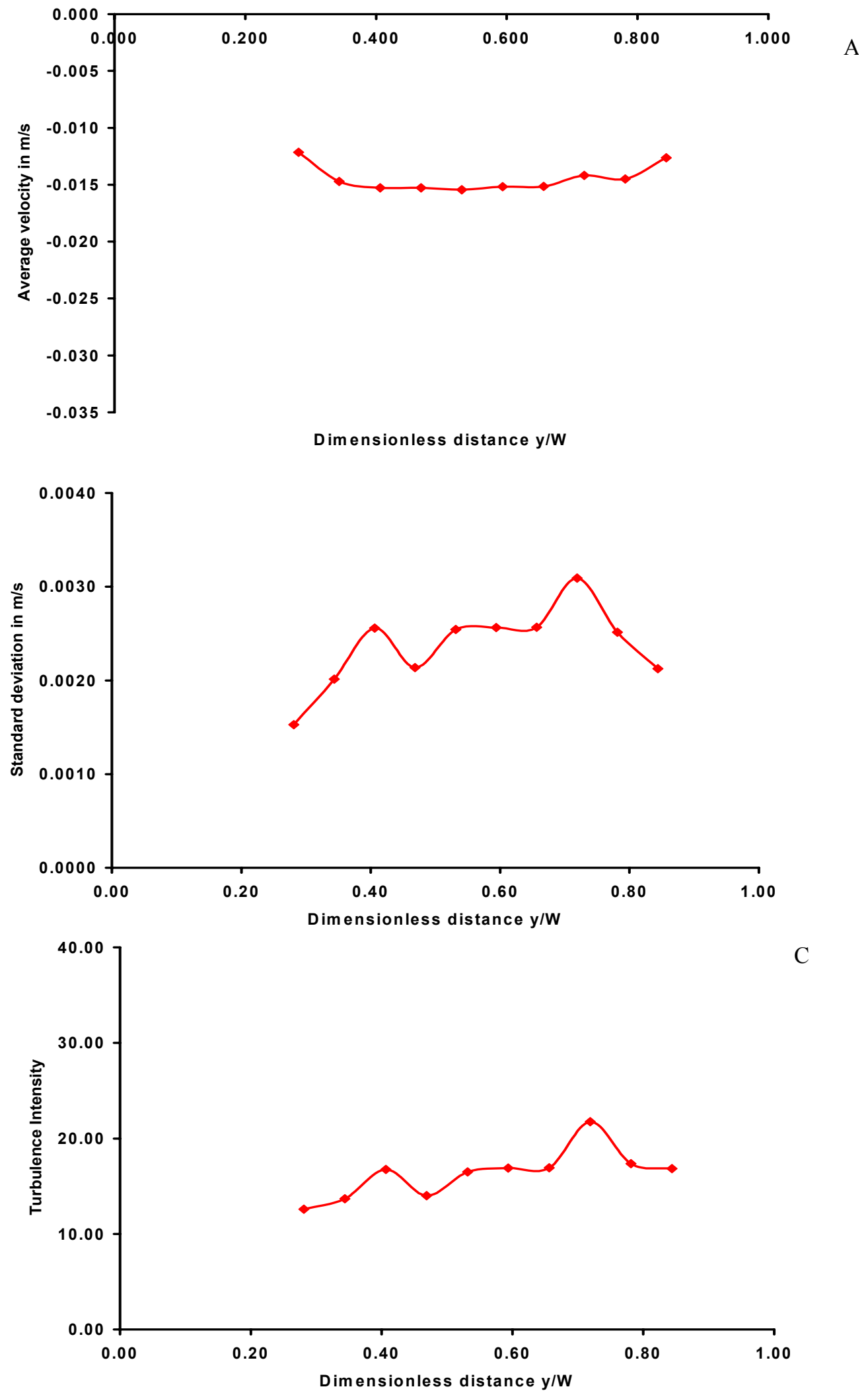

Fig. 4.2.2 LDV velocity data versus dimensionless distance for 0.5 inch traverse (Center) (Run \# 2; downflow; 2.2 deg ccw tilt )

A) Mean velocity B) Standard deviation C) Turbulence Intensity 

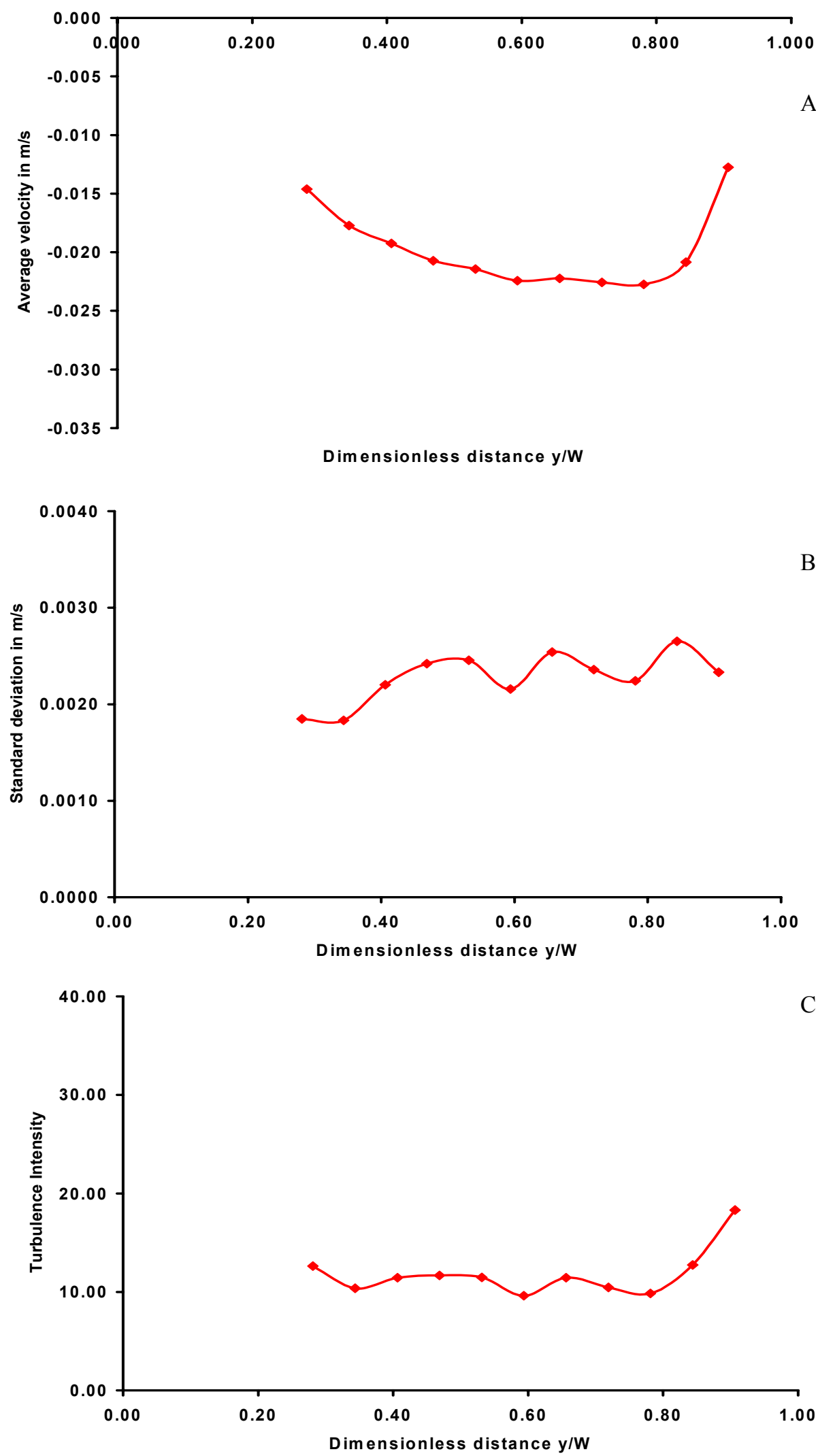

Fig 4.2.3 LDV velocity data versus dimensionless distance for 0.5 inch traverse (Back end) (Run \# 2; downflow; 2.2 deg ccw tilt )

A) Mean velocity B) Standard deviation C) Turbulence Intensity 


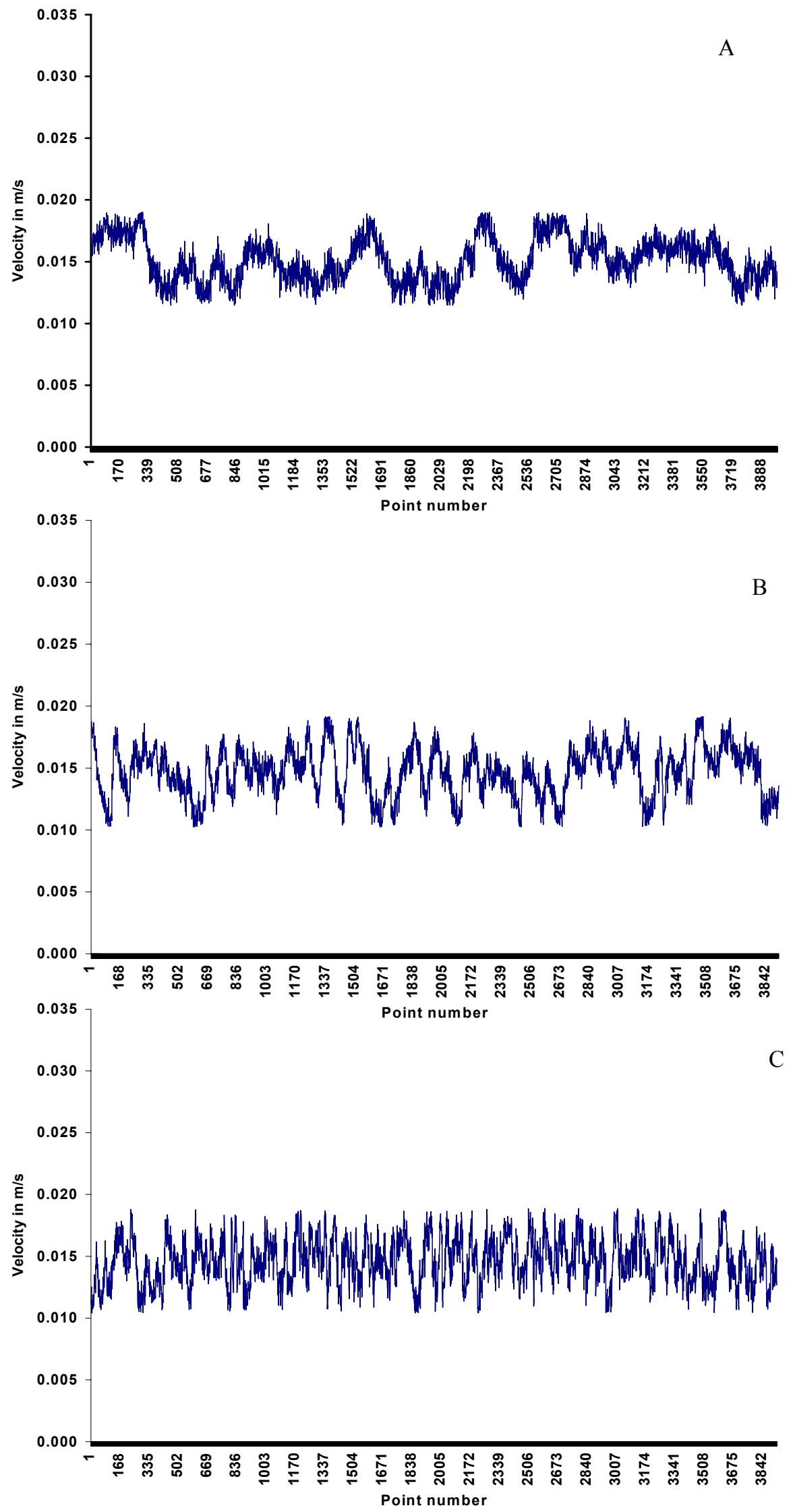

Fig. 4.2.4 LDV data series for different traverses (Run \#2; downflow; 2.2 deg ccw tilt) A) 1.5 inch traverse B) 0.5 inch traverse (Center) C) 0.5 inch traverse (Back end) 

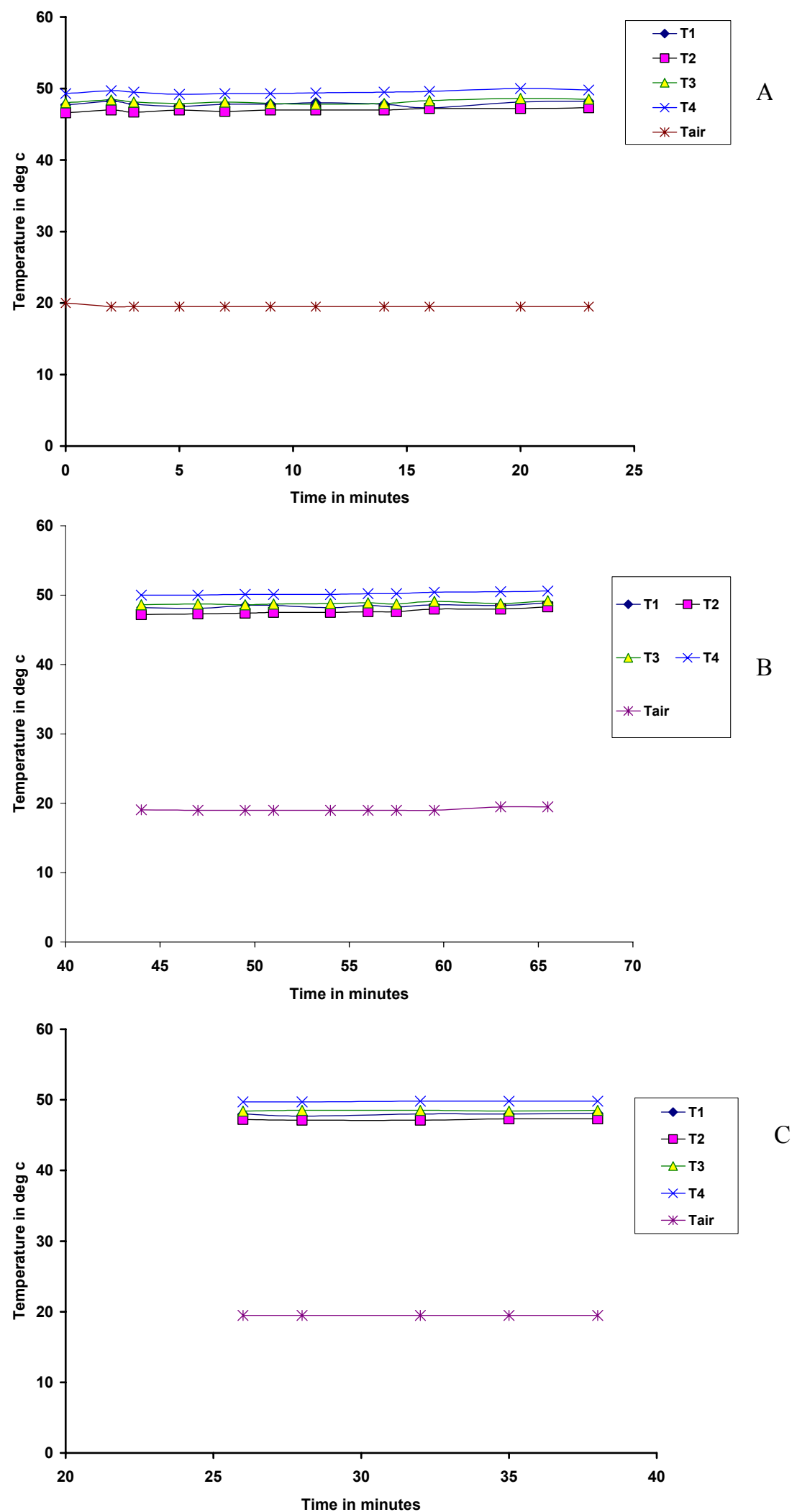

Fig. 4.2.5 Variation of temperature with respect to time for different traverses ( run \#2; downflow; 2.2 deg cew tilt)

A) 1.5 inch traverse B) 0.5 inch traverse (Center) C) 0.5 inch traverse (Back end) 

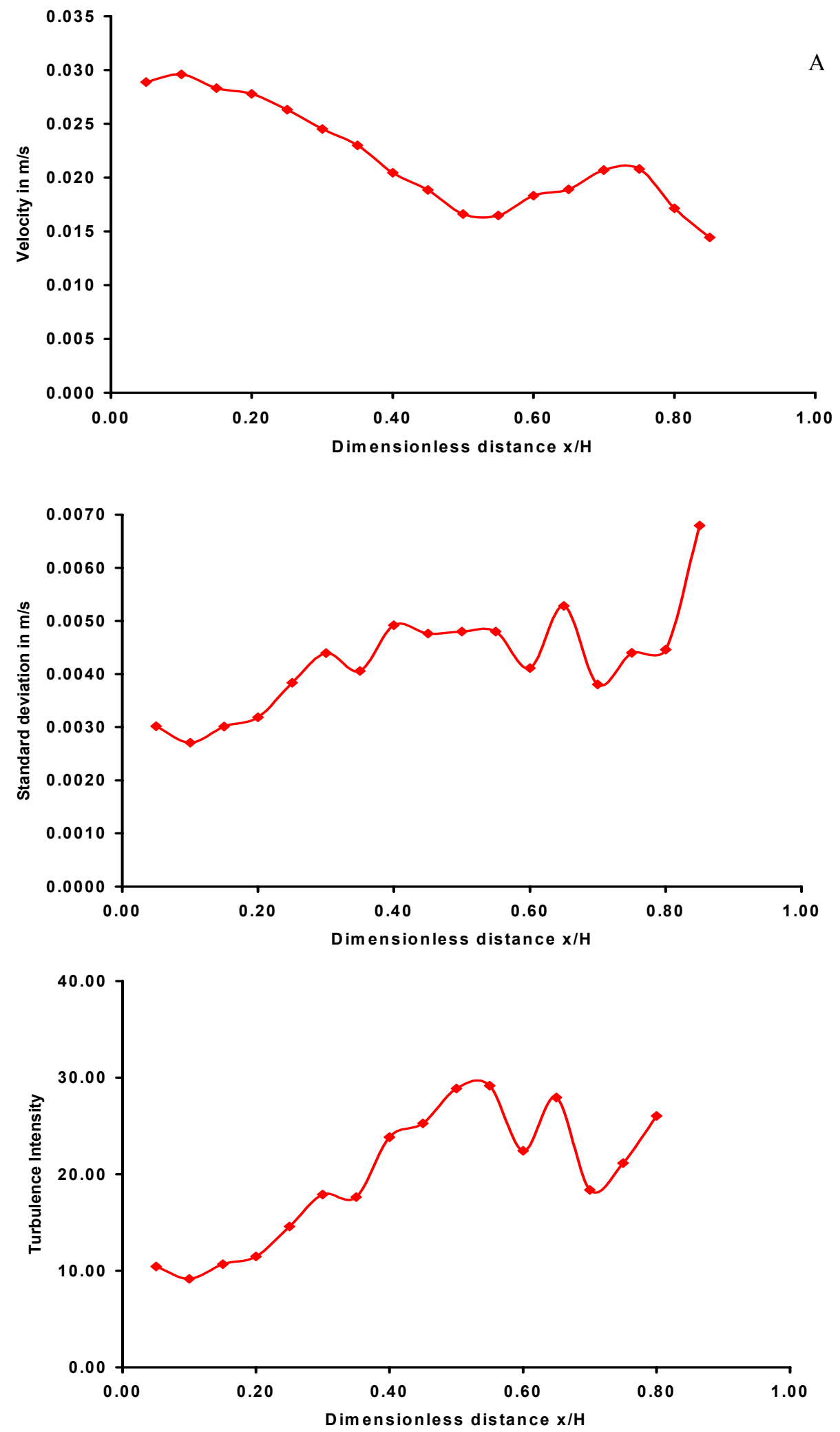

Fig. 4.3.1 LDV velocity data versus dimensionless distance for 1.5 inch traverse (Run \# 3; upflow; 2.1 deg cw tilt )

A) Mean velocity B) Standard deviation C) Turbulence Intensity 

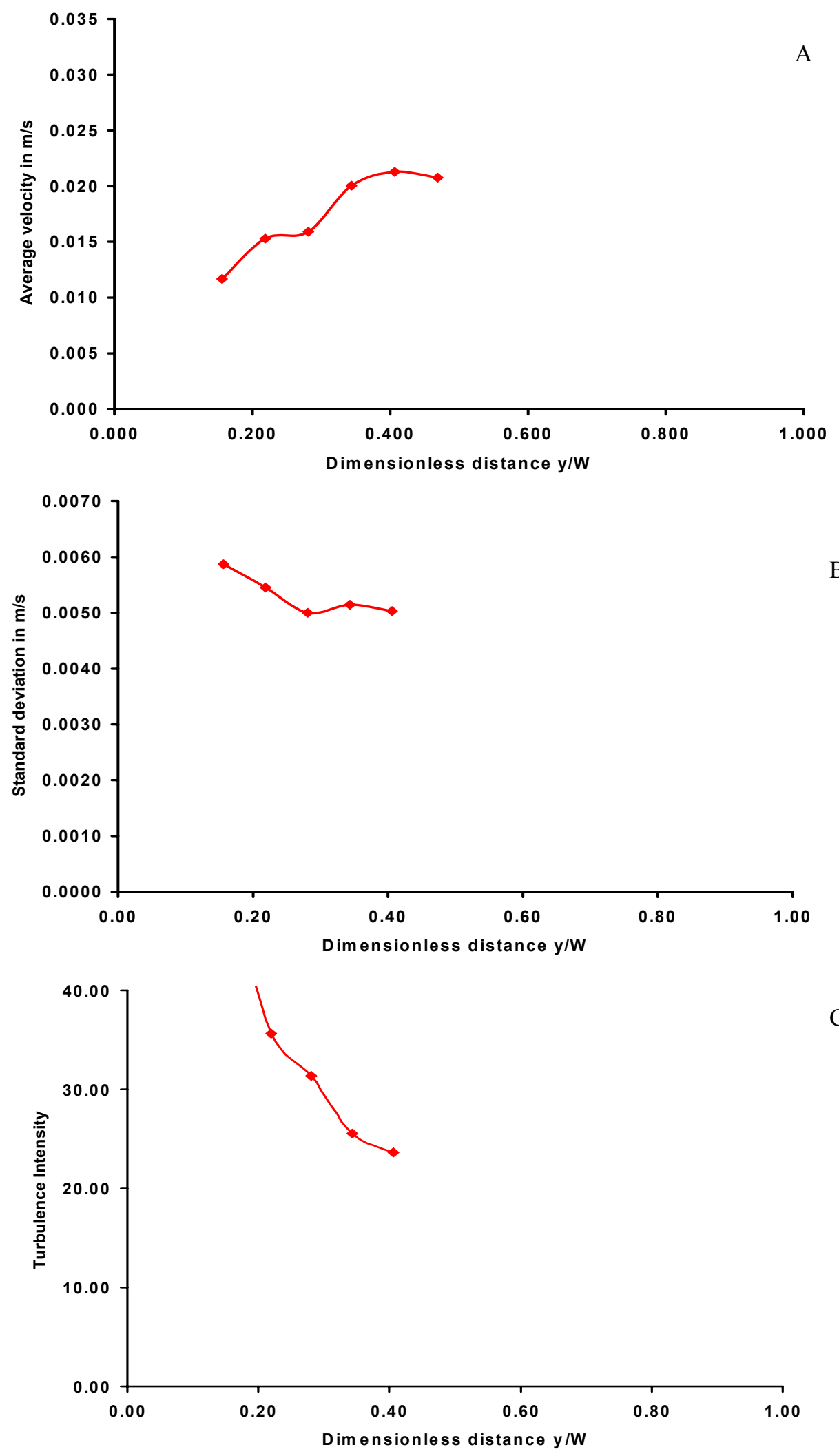

Fig. 4.3.2 LDV velocity data versus dimensionless distance for 0.5 inch traverse (Center) (Run \# 3; Upflow; 2.1 deg cw tilt )

A) Mean velocity B) Standard deviation C) Turbulence Intensity 

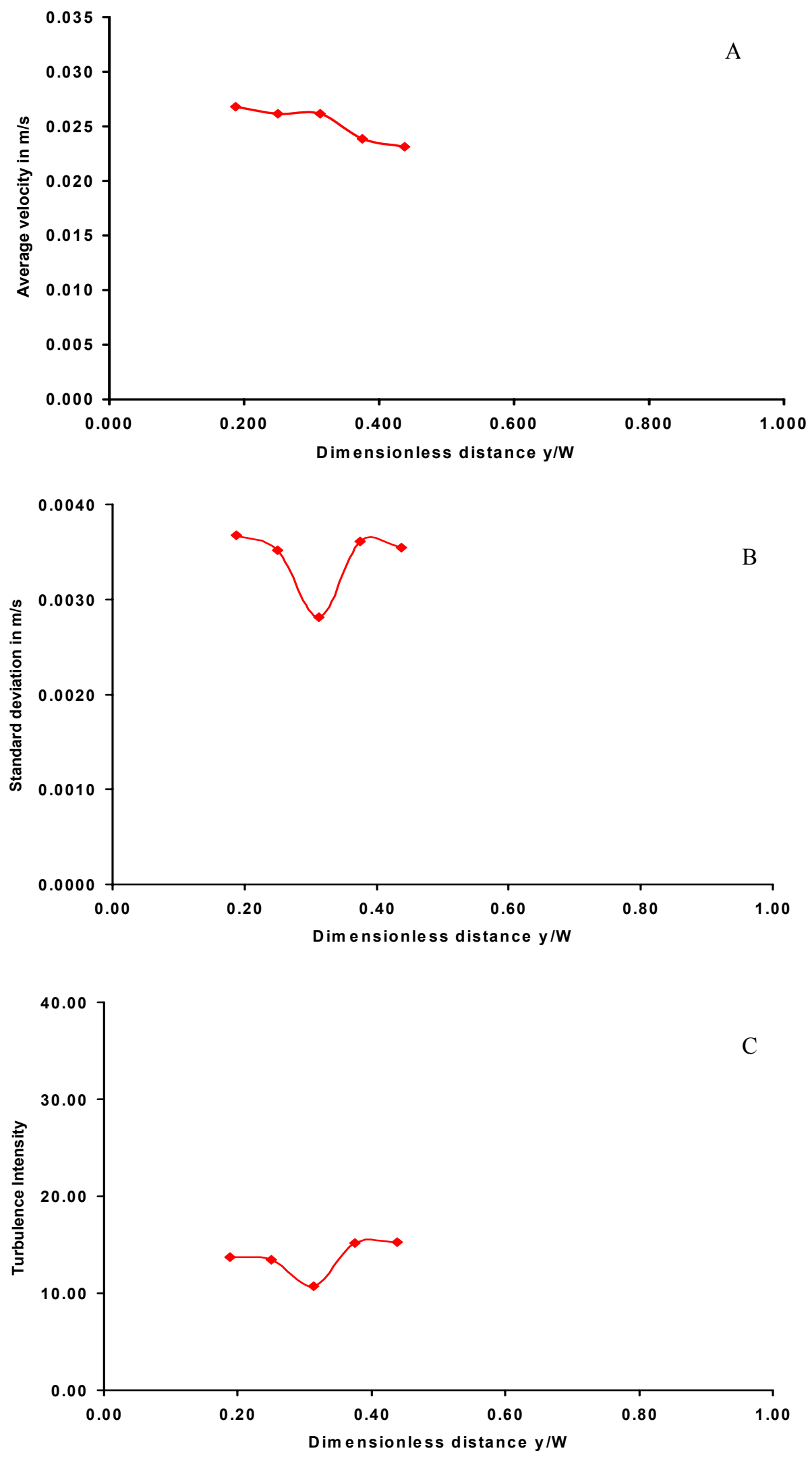

Fig. 4.3.3 LDV velocity data versus dimensionless distance for 0.5 inch traverse (Back end) (Run \# 3; Upflow; 2.1 deg cw tilt )

A) Mean velocity B) Standard deviation C) Turbulence Intensity 

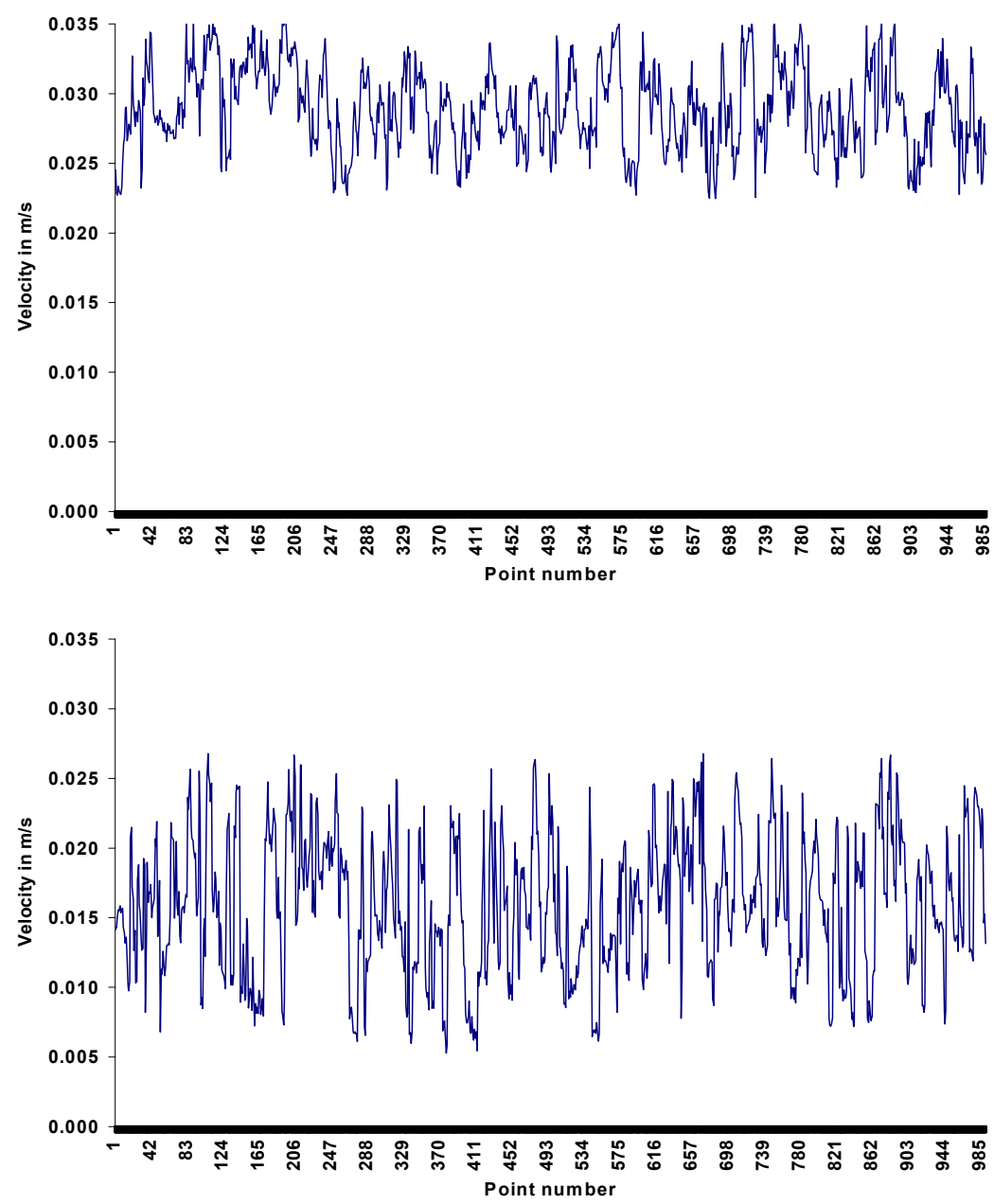

B

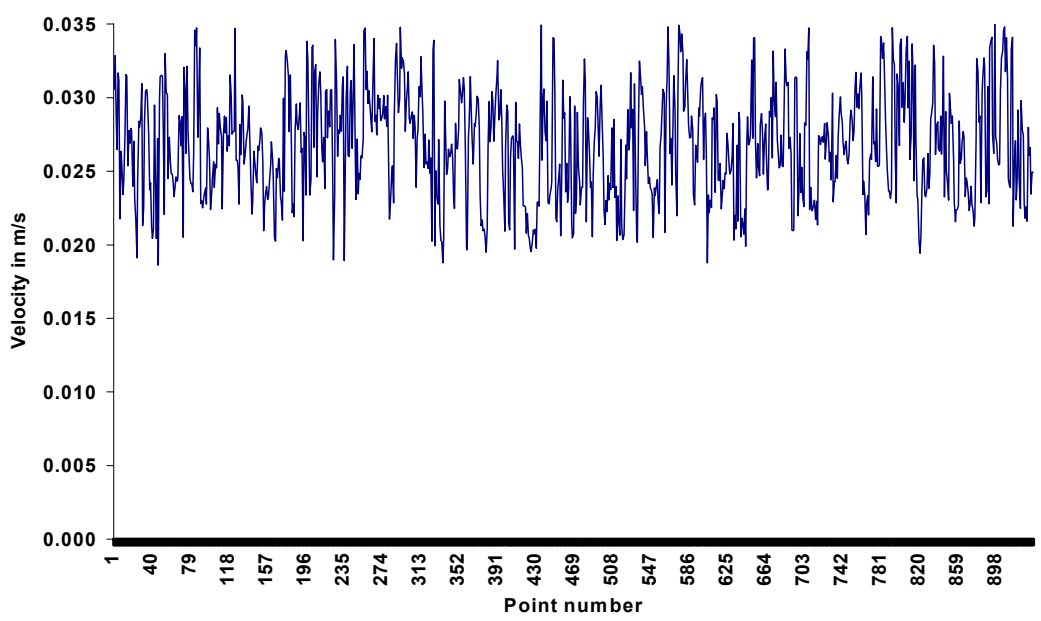

Fig. 4.3.4 LDV data series for different traverses (run \#3; upflow; $2.1 \mathrm{deg} \mathrm{cw}$ tilt) A) 1.5 inch traverse B) 0.5 inch traverse(Center) C) 0.5 inch traverse(Back end) 


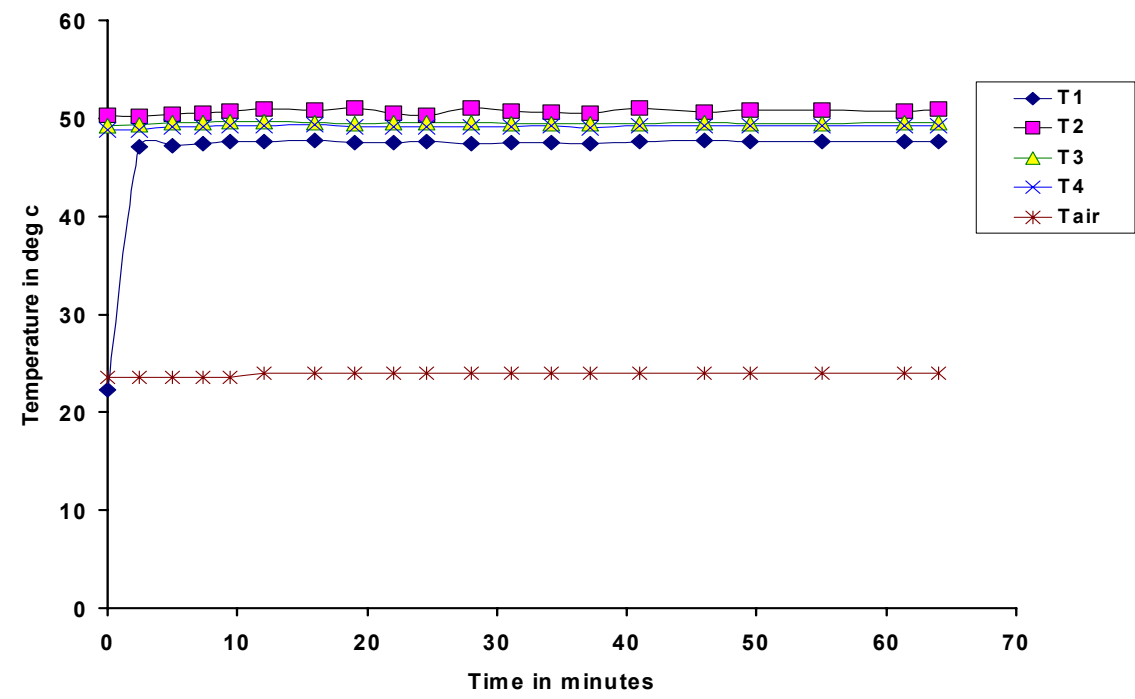

A

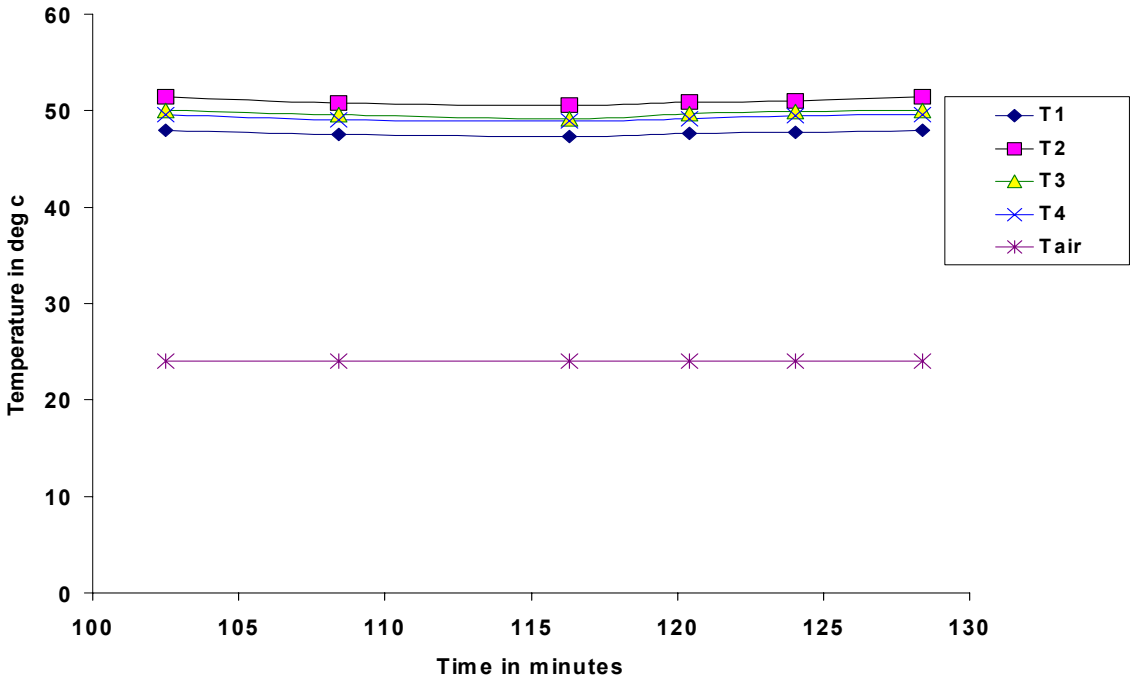

B

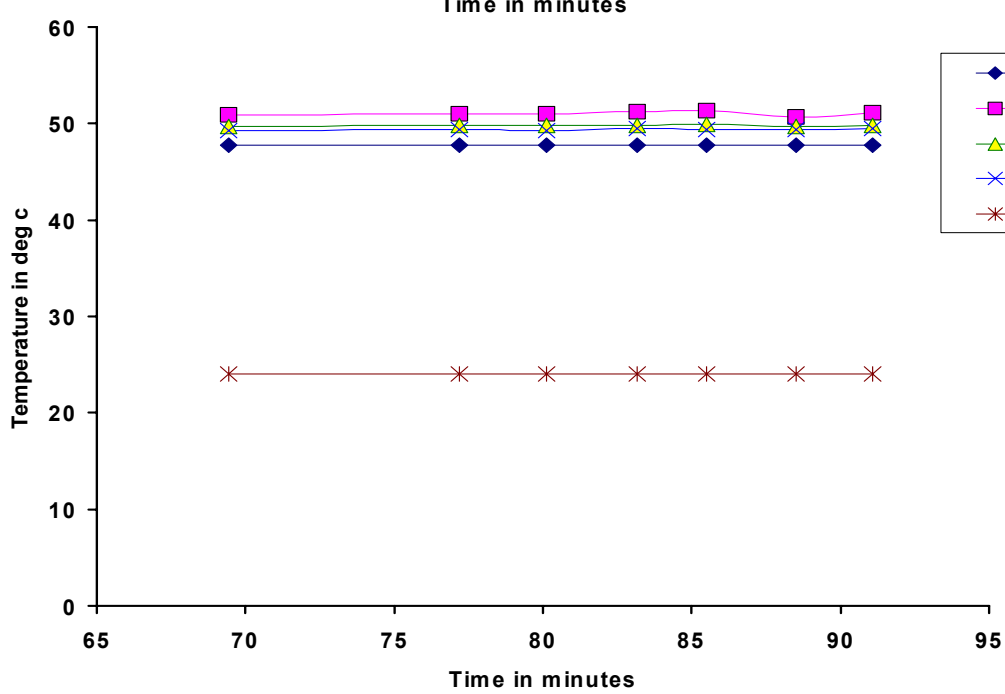

Fig. 4.3.5 Variation of temperature with respect to time for different traverses ( run \#3; upflow; $2.1 \mathrm{deg} \mathrm{cw}$ tilt)

A) 1.5 inch traverse B) 0.5 inch traverse (Center) C) 0.5 inch traverse (Back end) 

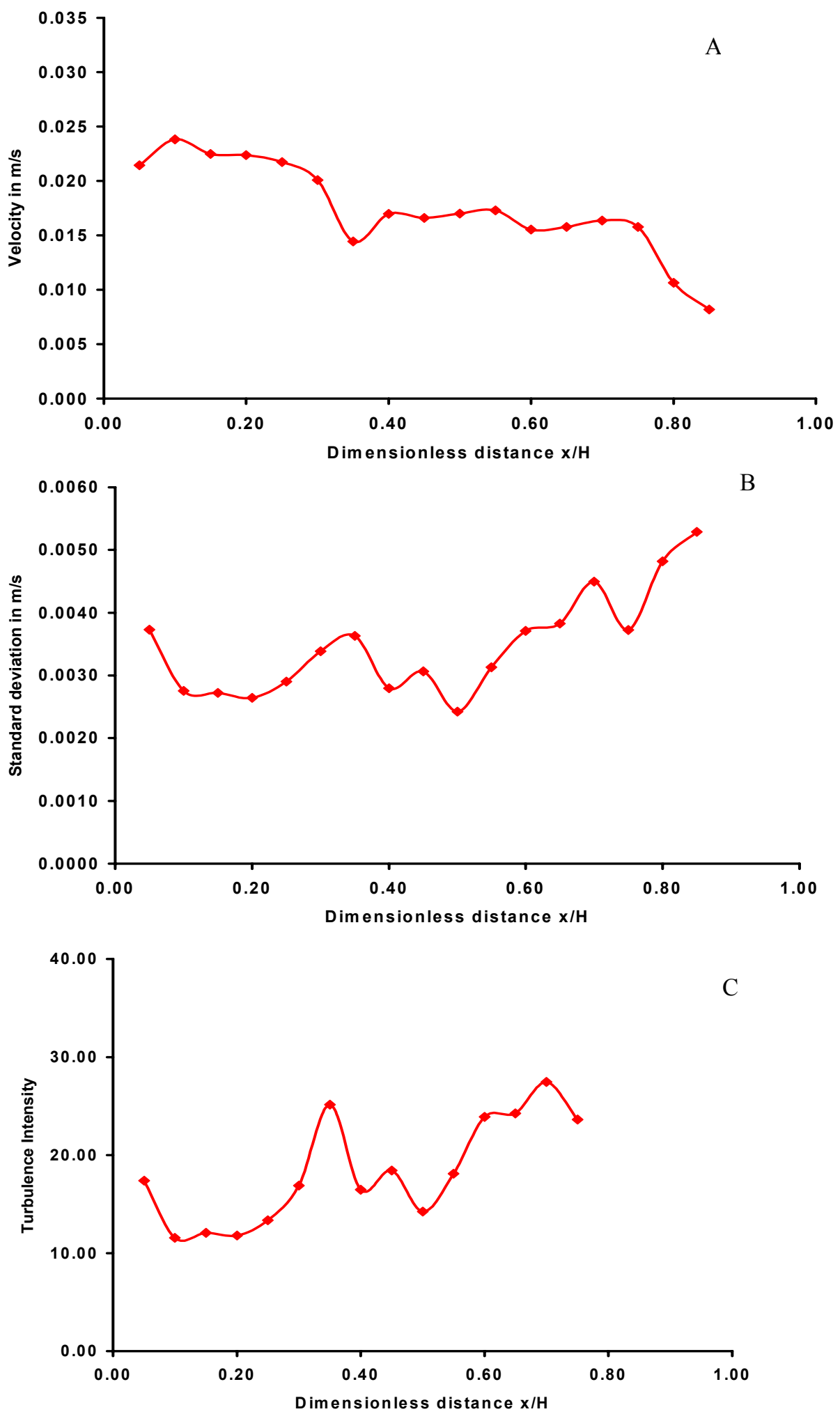

Fig. 4.4.1 LDV velocity data versus dimensionless distance for 1.5 inch traverse (Run \# 4; upflow; 2.1 deg cw tilt)

A) Mean velocity B) Standard deviation C) Turbulence Intensity 

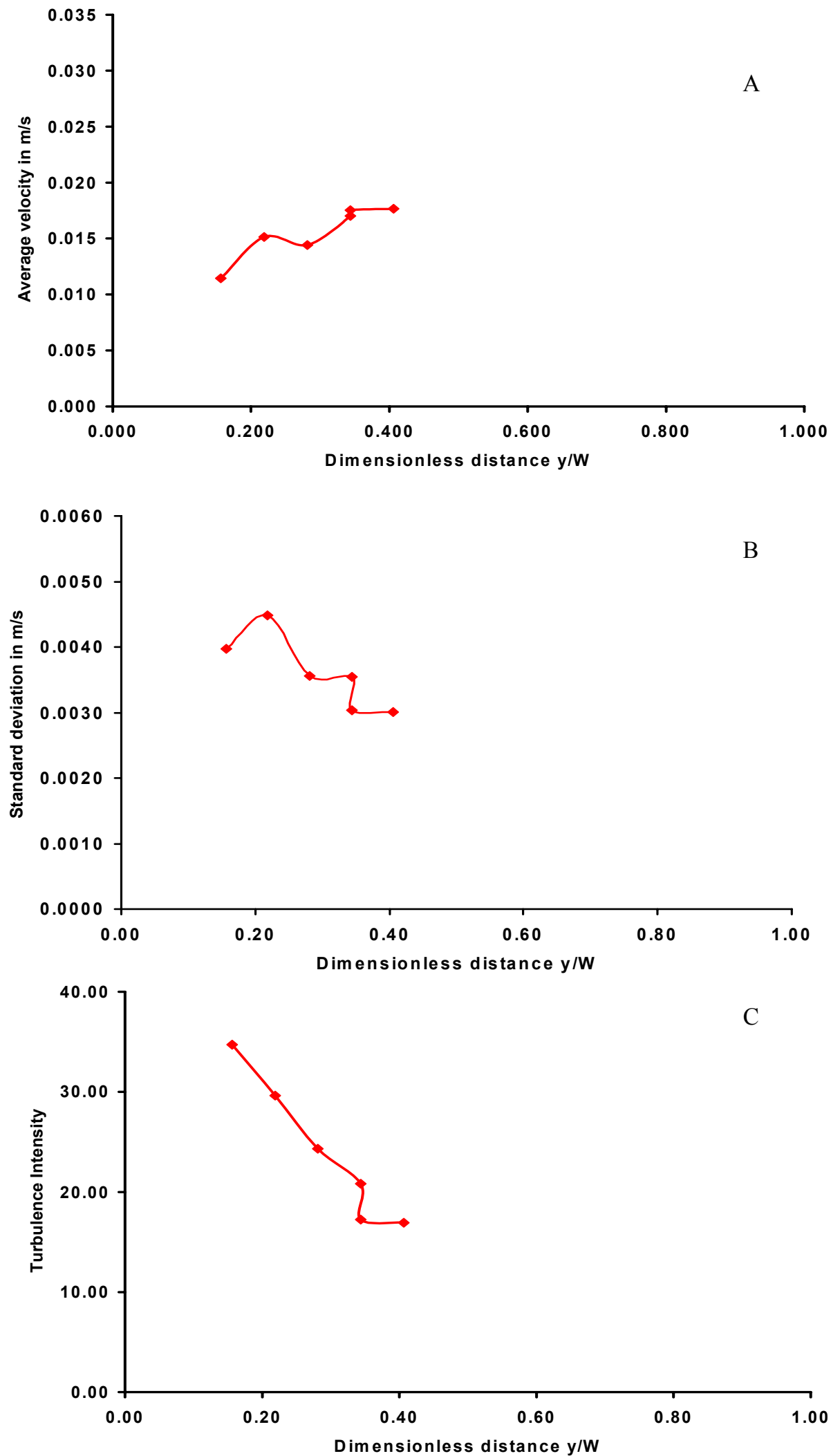

Fig. 4.4.2 LDV velocity data versus dimensionless distance for 0.5 inch traverse (Center) (Run \# 4; Upflow; 2.1 deg cw tilt )

A) Mean velocity B) Standard deviation C) Turbulence Intensity 

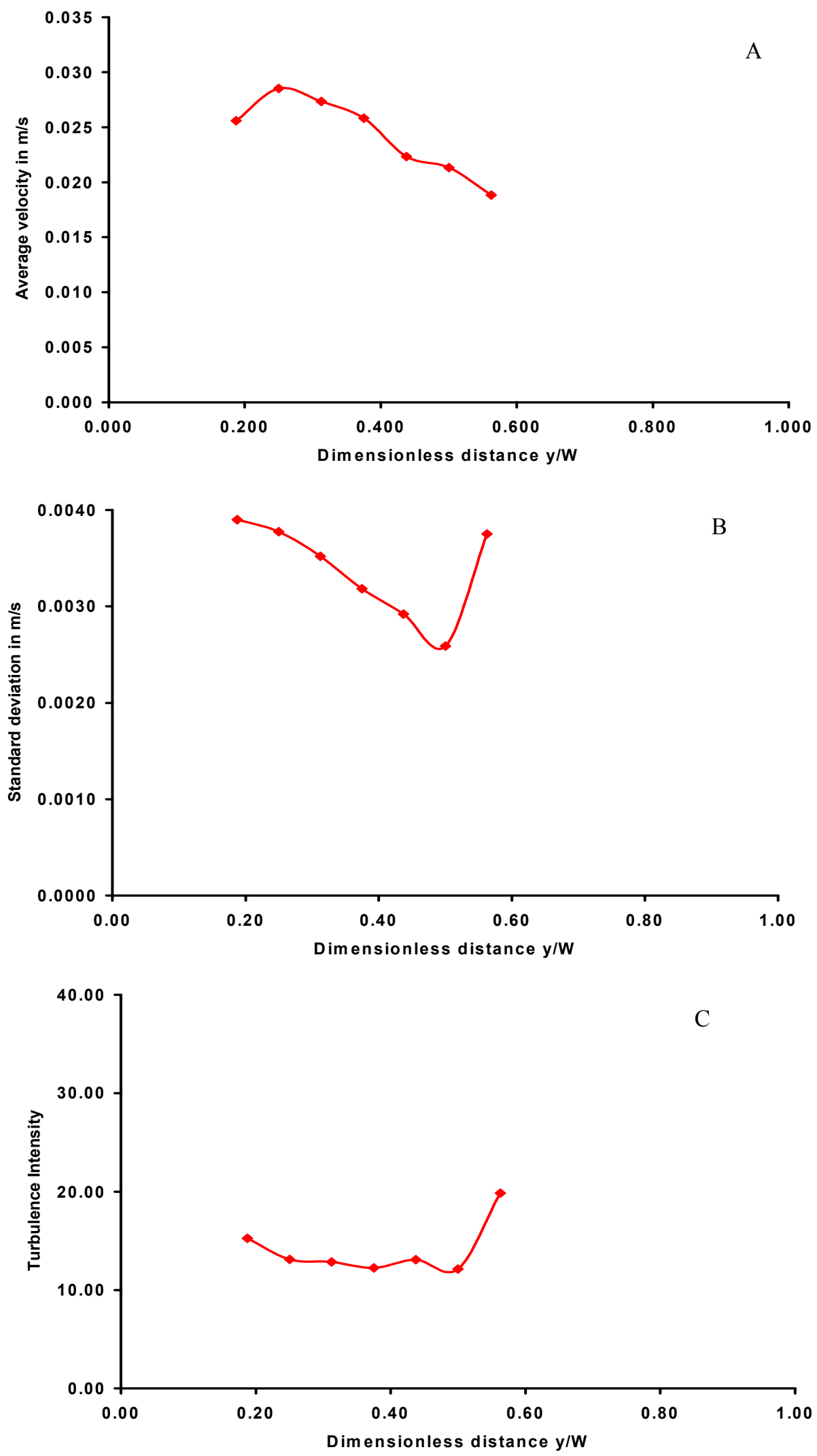

Fig. 4.4.3 LDV velocity data versus dimensionless distance for 0.5 inch traverse (Back end) (Run \# 4; Upflow; 2.1 deg cw tilt )

A) Mean velocity B) Standard deviation C) Turbulence Intensity 

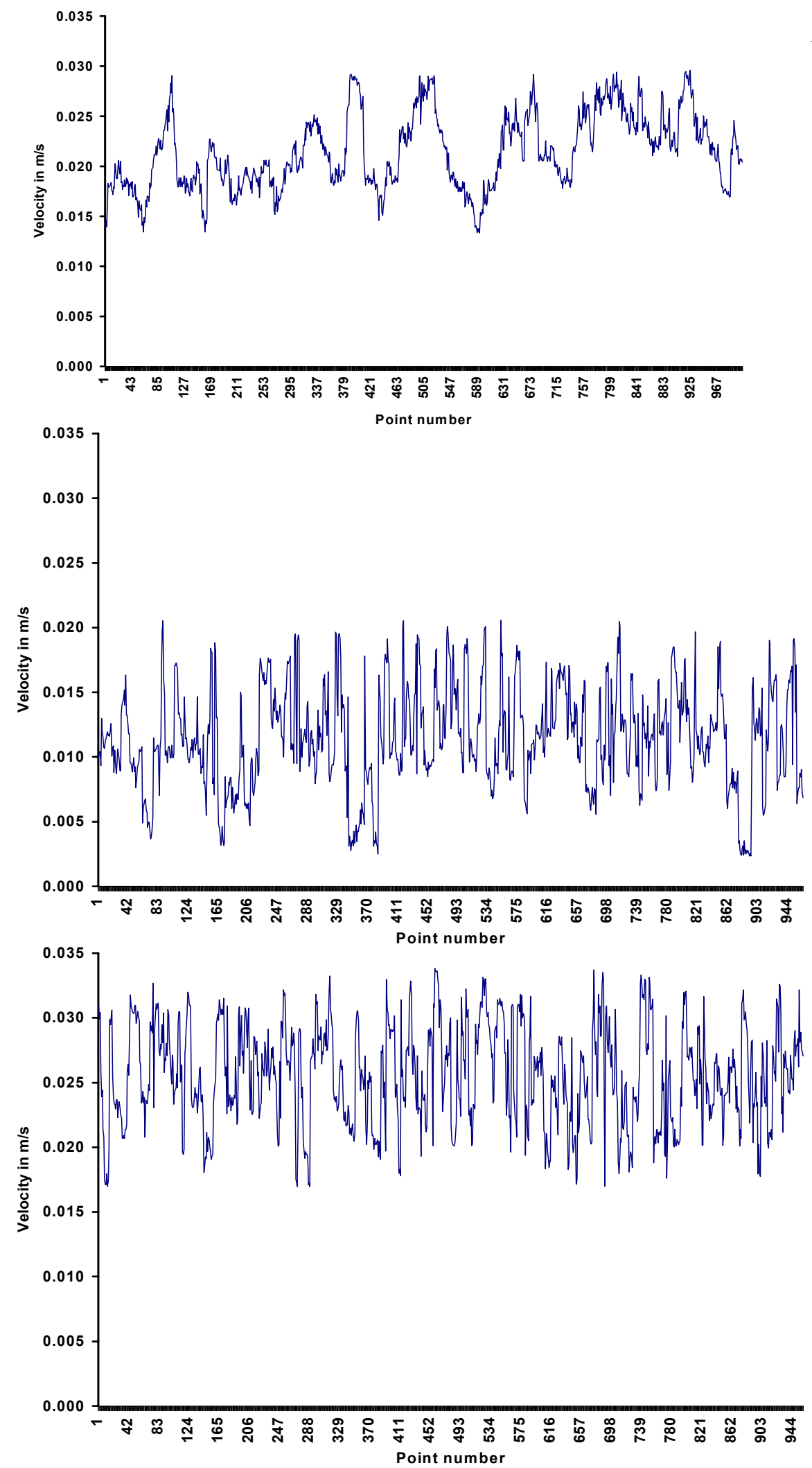

Fig. 4.4.4 LDV data series for different traverses ( run \#4; upflow; $2.1 \mathrm{deg} \mathrm{cw}$ tilt) A) 1.5 inch traverse B) 0.5 inch traverse(Center) C) 0.5 inch traverse(Back end) 


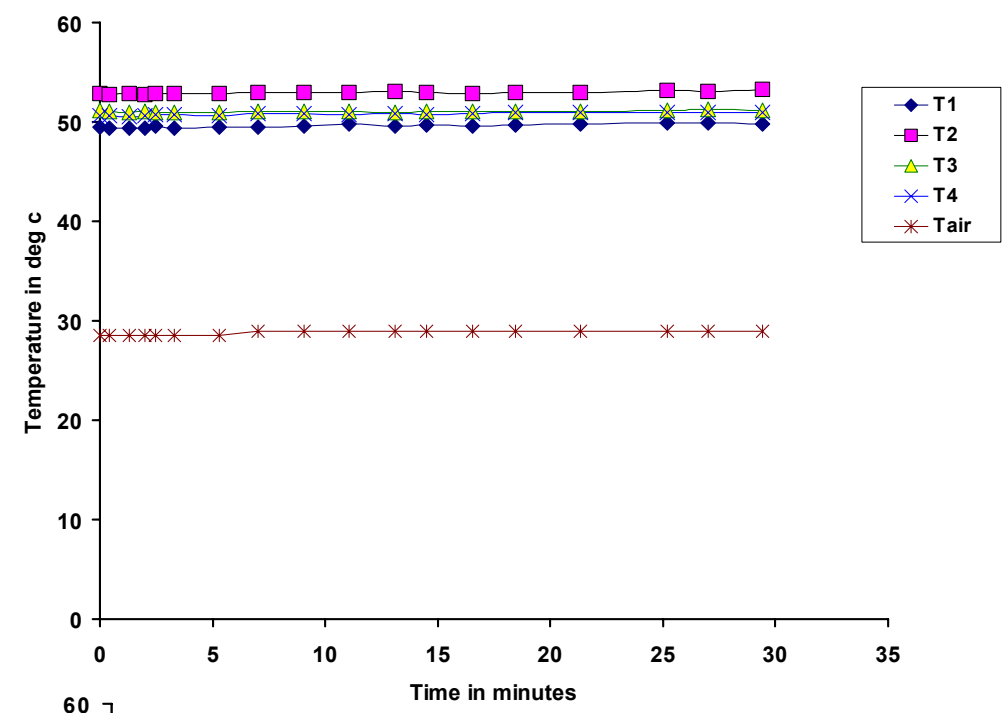

A
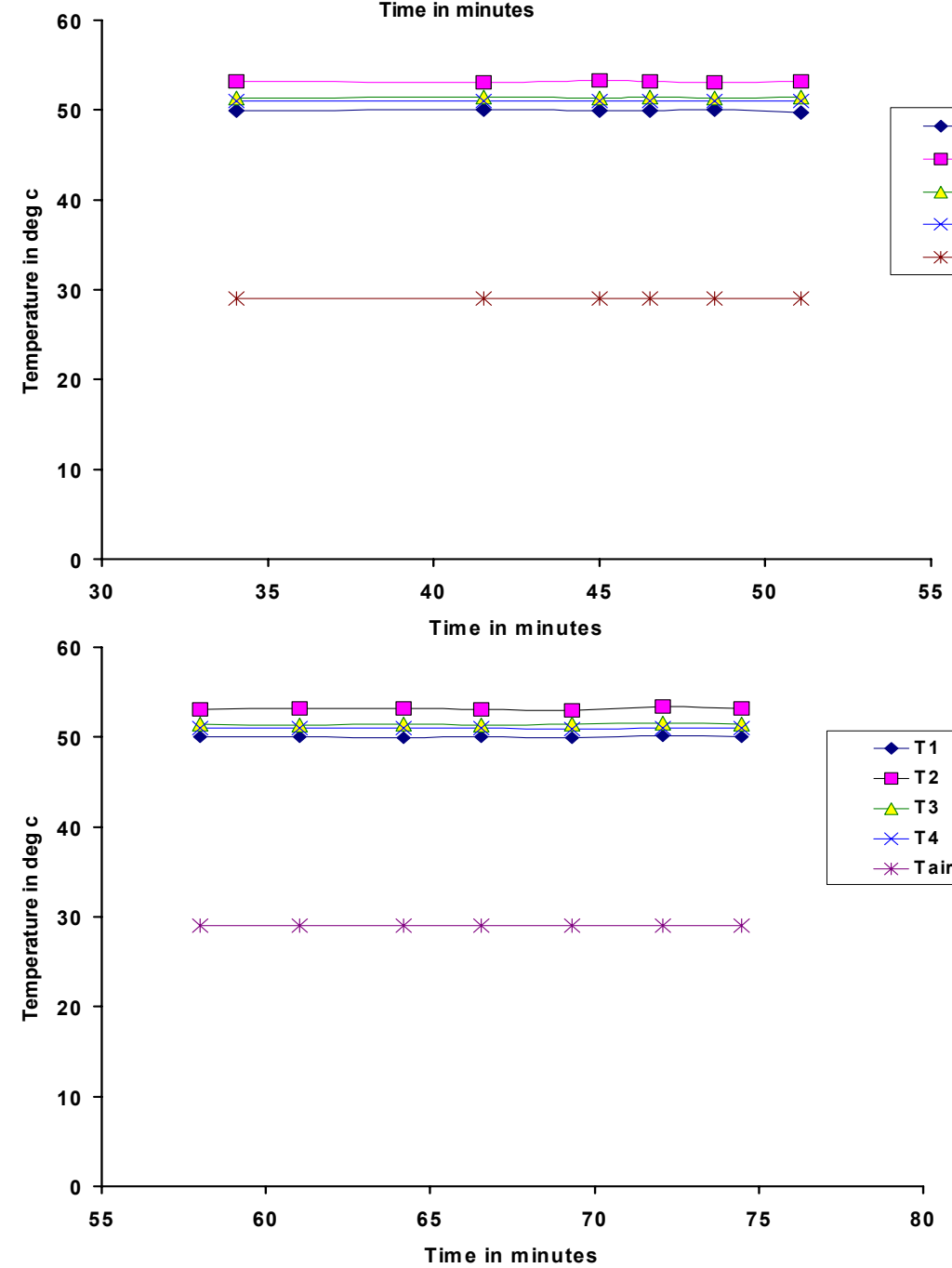

Fig. 4.4.5 Variation of temperature with respect to time for different traverses (Run \#4; upflow; 2.1 deg cw tilt)

A) 1.5 inch traverse B) 0.5 inch traverse (Center) C) 0.5 inch traverse (Back end) 

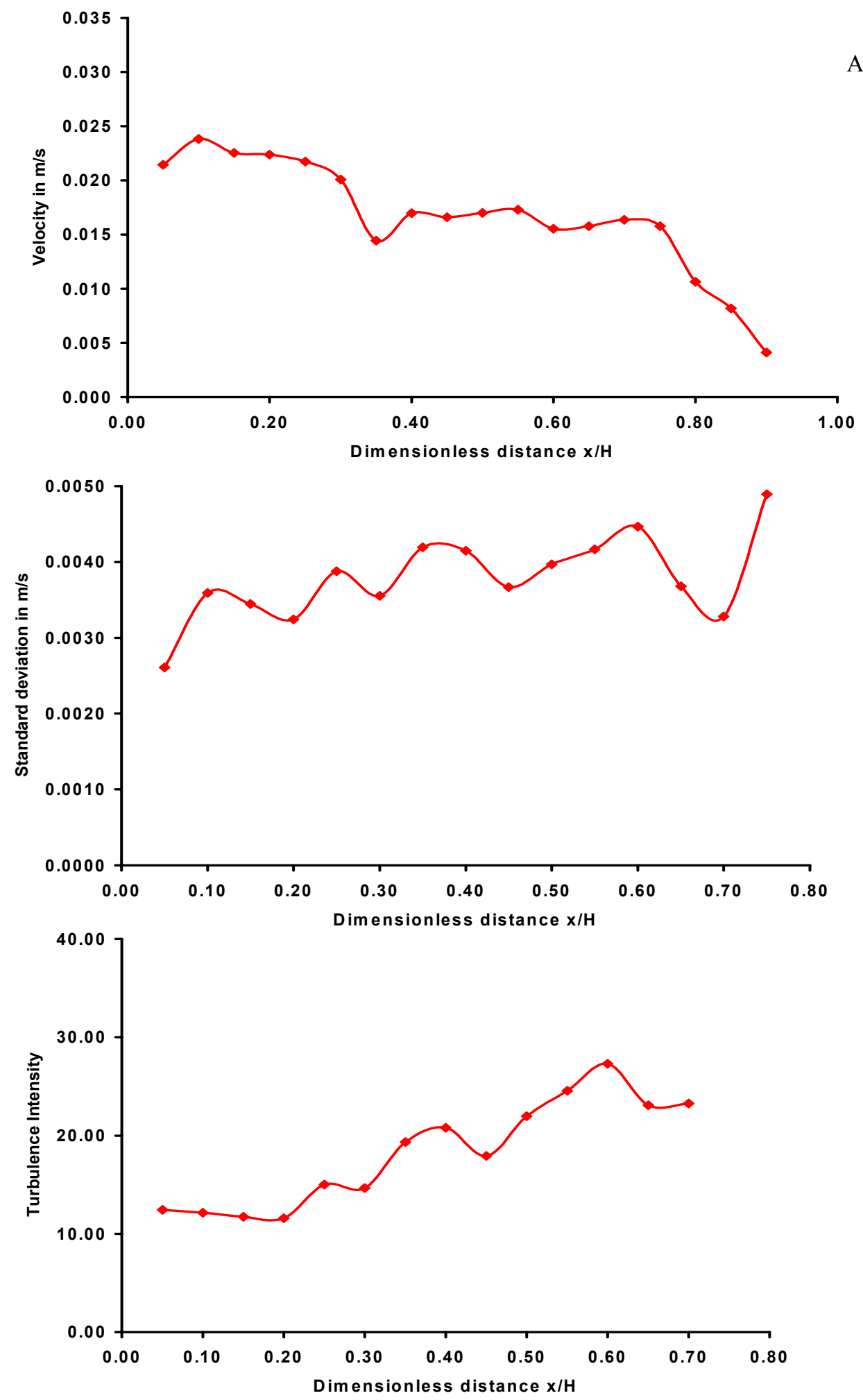

Fig. 4.5.1 LDV velocity data versus dimensionless distance for 1.5 inch traverse (Run \# 5; Upflow; $0 \pm 0.1$ deg tilt)

A) Mean velocity B) Standard deviation C) Turbulence Intensity 


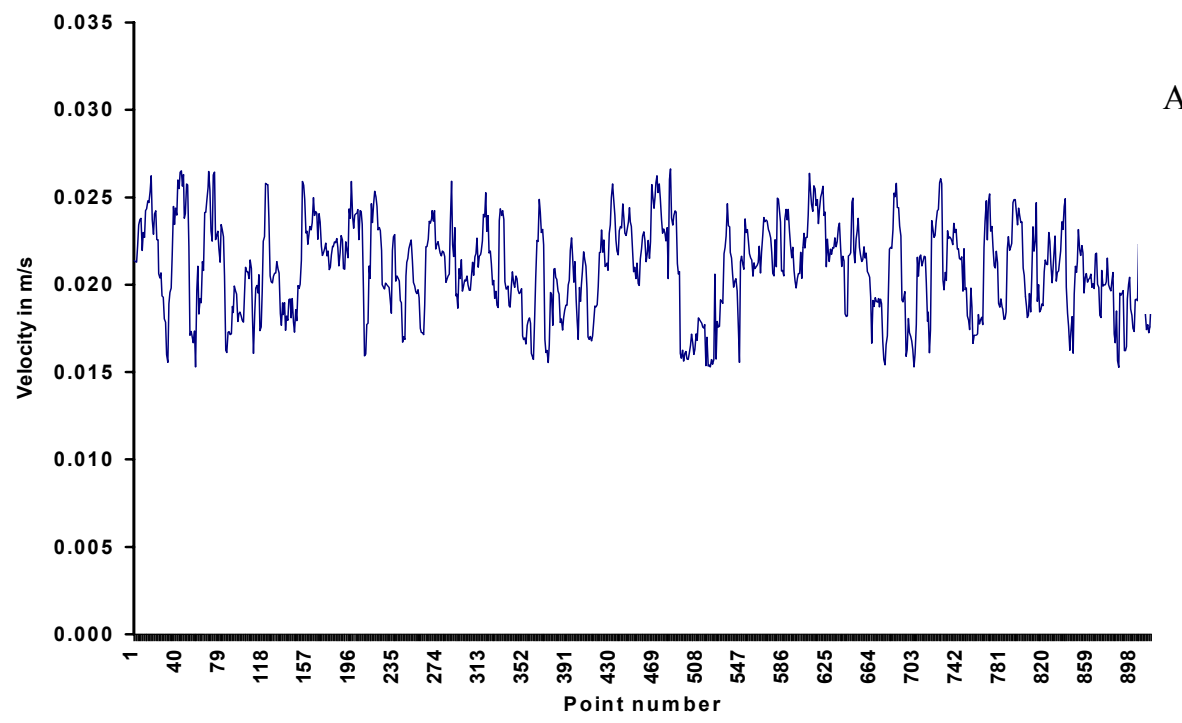

A
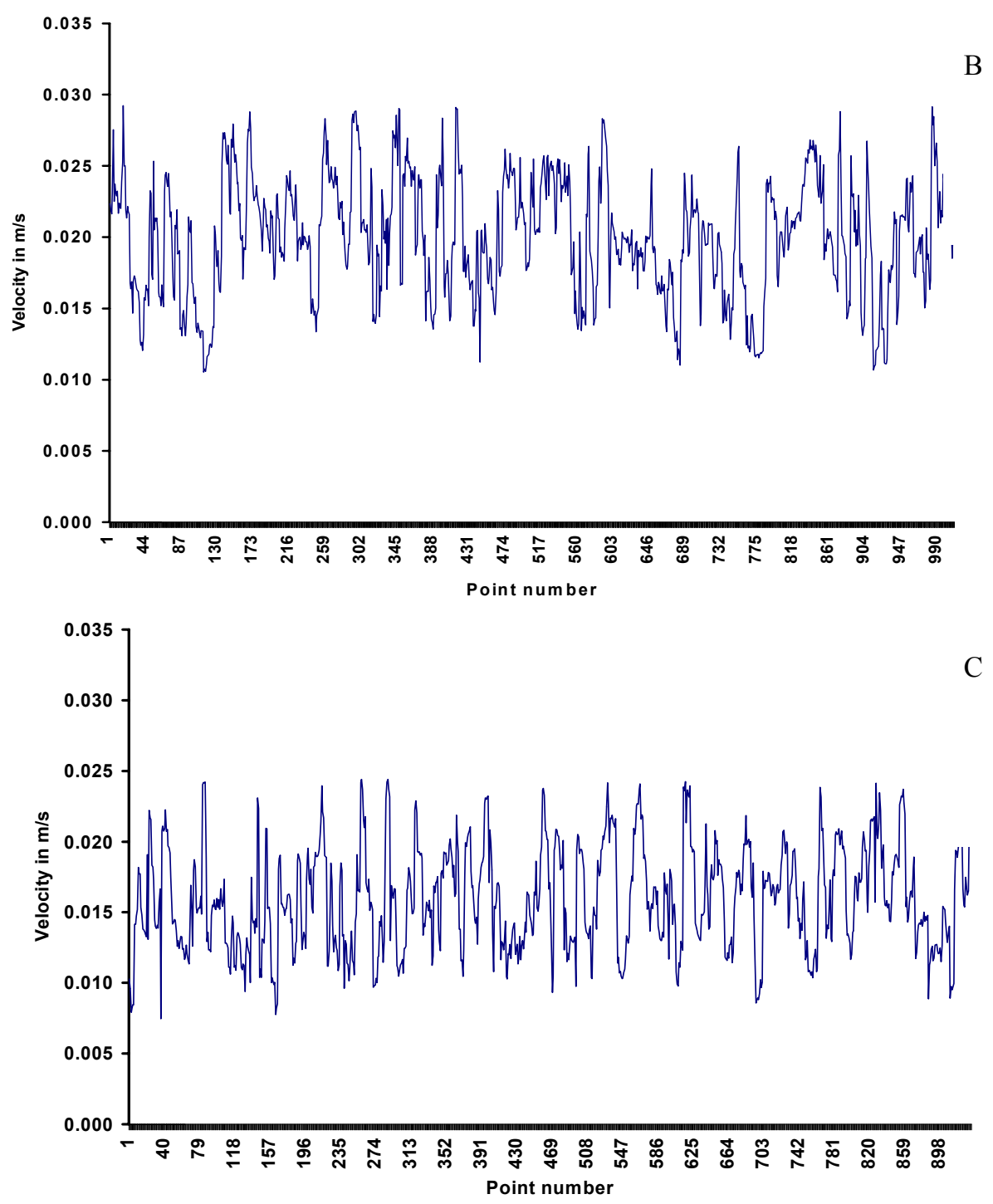

Fig. 4.5.2 LDV data series for 1.5 inch traverse at different locations (Run \# 5; Upflow; $0 \pm 0.1$ deg tilt)

A) Back end B) Center C) Front end 


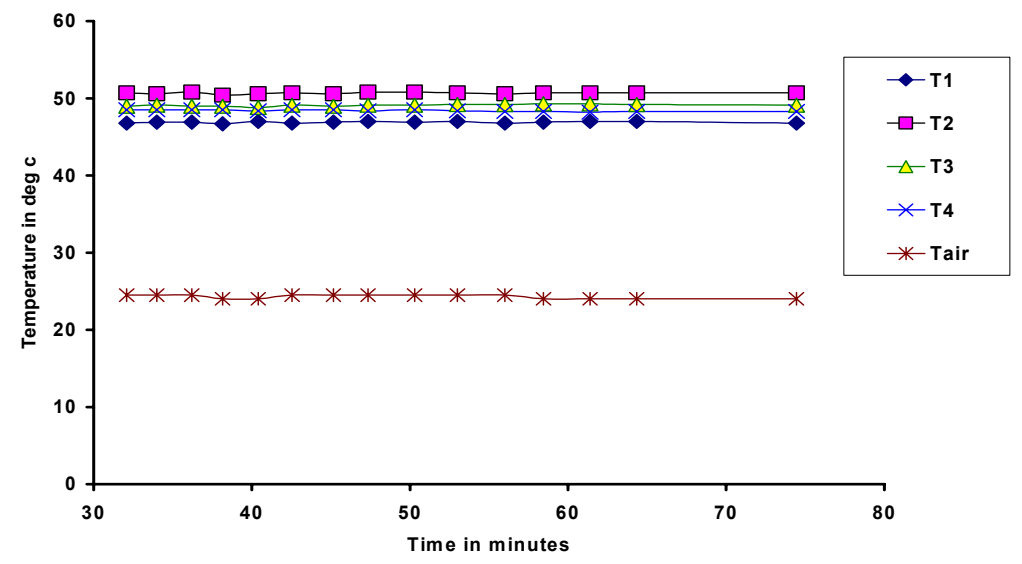

Fig. 4.5.3 Variation of temperature with respect to time for 1.5 inch traverse ( Run \# 5: Upflow: $0 \pm 0.1$ degree tilt of the setup) 


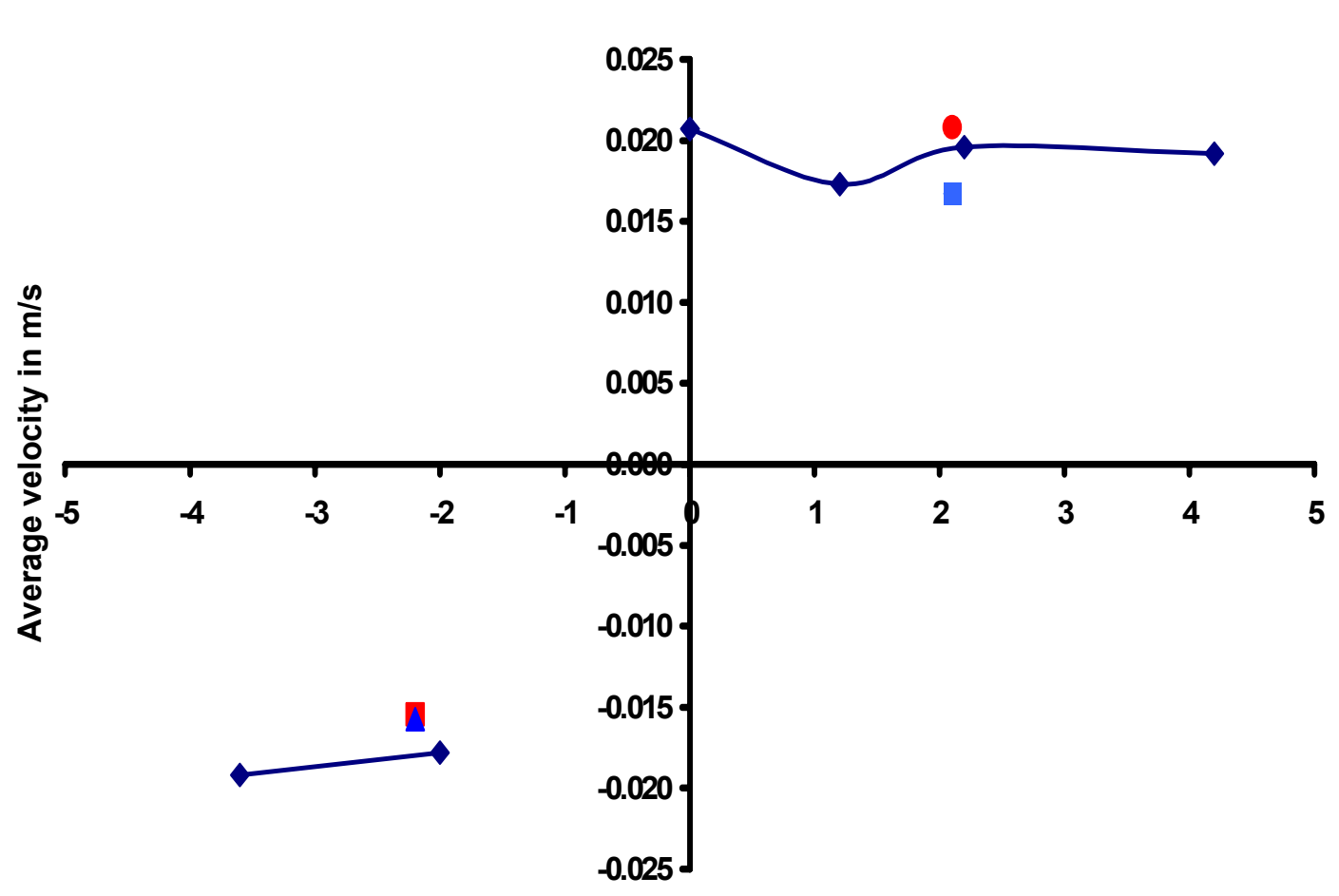

A

Angle of tilt in degrees

B

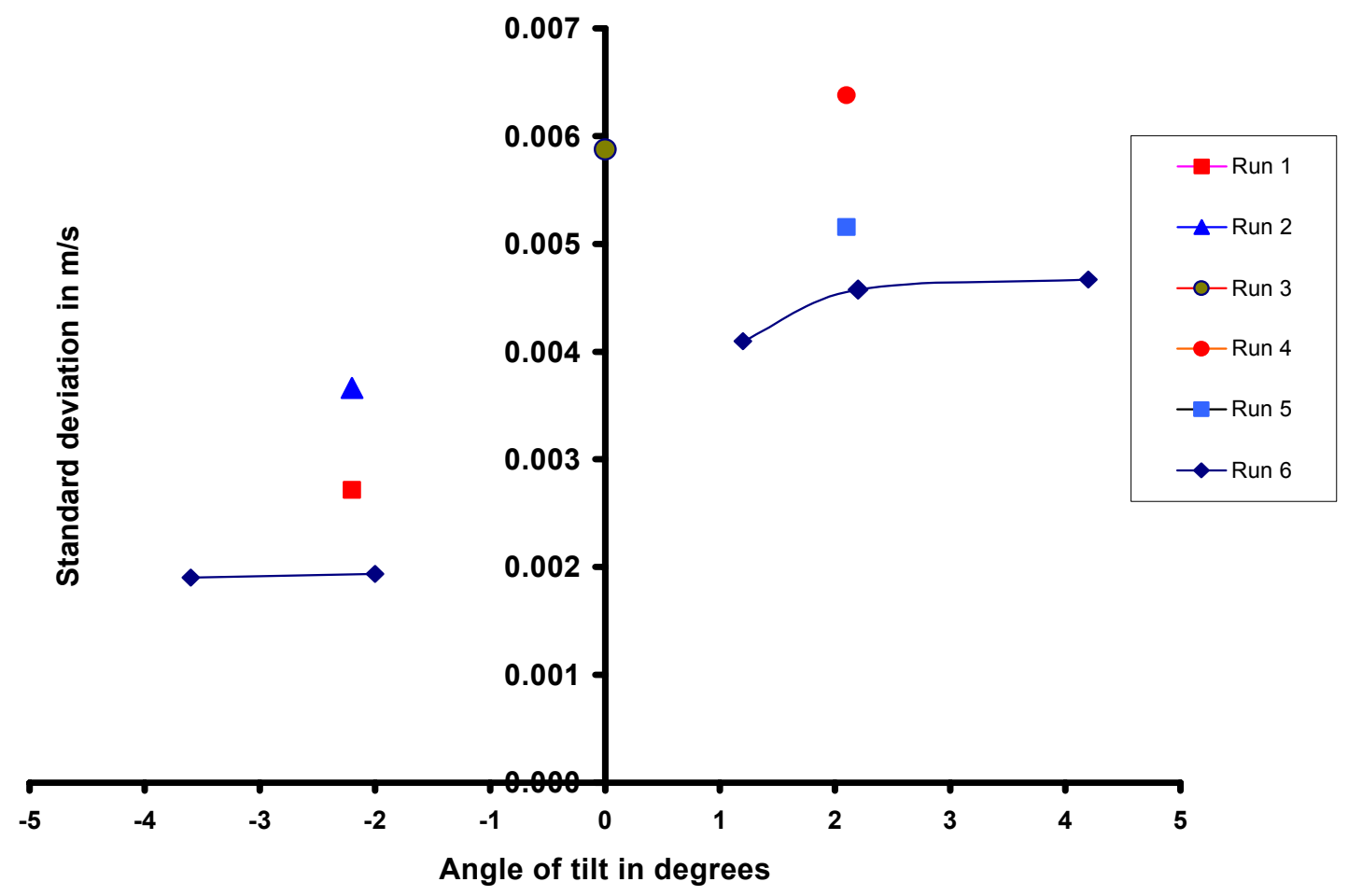

Fig. 4.6.1 LDV velocity data on the centerline for various angles of tilt of the setup A) Average velocity B) Standard Deviation 
TABLE 4.1 SUMMARY OF RESULTS FOR DIFFERENT RUNS

\begin{tabular}{|c|c|c|c|c|c|c|}
\hline $\begin{array}{c}\text { Run } \\
\text { number }\end{array}$ & $\begin{array}{c}\text { Flow } \\
\text { direction }\end{array}$ & $\begin{array}{c}\text { Tilt angle } \\
\text { in degrees }\end{array}$ & $\begin{array}{c}\text { Qheating in } \\
\text { watts }\end{array}$ & $\begin{array}{c}Q_{\text {cooling }} \text { in } \\
\text { watts }\end{array}$ & $\begin{array}{c}\mathrm{V}_{\text {predicted }} \text { in } \\
\mathrm{cm} / \mathrm{s}\end{array}$ & $\begin{array}{c}\mathrm{V}_{\text {observed }} \\
\mathrm{cm} / \mathrm{s}\end{array}$ \\
\hline 1 & Downflow & $2.2 \mathrm{cw}$ & & & & 1.42 \\
\hline 2 & Downflow & $2.2 \mathrm{cw}$ & 50.58 & 27.13 & 7.59 & 1.7 \\
\hline 3 & Upflow & $2.1 \mathrm{ccw}$ & 96.24 & 32 & 6.36 & 2.14 \\
\hline 4 & Upflow & $2.1 \mathrm{ccw}$ & 69.2 & 18.8 & 6.54 & 1.88 \\
\hline 5 & Upflow & $0 \pm 0.1$ & 81 & 32.17 & 7.67 & 2.07 \\
\hline
\end{tabular}


TABLE 4.2 SUMMARY OF RESULTS FOR VARIOUS ANGLES OF TILT

\begin{tabular}{|c|c|c|c|c|c|}
\hline $\begin{array}{l}\text { Angle of tilt } \\
\text { in degrees }\end{array}$ & $\begin{array}{c}\text { Flow } \\
\text { Direction }\end{array}$ & $\begin{array}{c}\text { Qheating in } \\
\text { watts }\end{array}$ & $\begin{array}{c}\mathrm{Q}_{\text {cooling in }} \\
\text { watts }\end{array}$ & $\begin{array}{c}\mathrm{V}_{\text {predicted }} \text { in } \\
\mathrm{cm} / \mathrm{s}\end{array}$ & $\begin{array}{c}\mathrm{V}_{\text {observed }} \text { in } \\
\mathrm{cm} / \mathrm{s}\end{array}$ \\
\hline $3.6 \mathrm{cw}$ & Downflow & 35.6 & 29.11 & 5.06 & 1.92 \\
\hline $2.0 \mathrm{cw}$ & Downflow & 33 & 41.98 & 5.32 & 1.78 \\
\hline $1.2 \mathrm{ccw}$ & Upflow & 49.6 & 26.23 & 5.32 & 1.73 \\
\hline $2.2 \mathrm{ccw}$ & Upflow & 66 & 26.41 & 5.32 & 1.93 \\
\hline $4.2 \mathrm{ccw}$ & Upflow & 58.2 & 25.87 & 4.79 & 1.92 \\
\hline
\end{tabular}


TABLE 4.3: ERROR ANALYSIS TABLE

\begin{tabular}{|c|c|c|c|c|}
\hline $\begin{array}{l}\text { Velocity } \\
\text { in } \mathrm{cm} / \mathrm{s}\end{array}$ & $\begin{array}{l}\text { Temperatur } \\
\text { e difference } \\
\text { at the } \\
\text { heaters } \\
\Delta \mathbf{T}_{\text {heating in }} \\
\text { Degree C }\end{array}$ & \begin{tabular}{|l|} 
Temperatur \\
e difference \\
at the \\
coolers \\
$\Delta \mathrm{T}_{\text {cooling in }}$ \\
Degree C
\end{tabular} & $\begin{array}{l}\mathbf{Q}_{\text {heating }} \\
\text { in Watts }\end{array}$ & $\begin{array}{l}Q_{\text {cooling }} \\
\text { in Watts }\end{array}$ \\
\hline 1.54 & & & & \\
\hline 1.35 & & & & \\
\hline 1.38 & & & & \\
\hline 1.57 & 1.855 & 0.97 & 49.05 & 25.73 \\
\hline 1.44 & 1.76 & 0.9 & 42.99 & 21.98 \\
\hline 1.98 & 1.79 & 1.01 & 59.71 & 33.69 \\
\hline 2.08 & 3.51 & 0.91 & 114.7 & 29.9 \\
\hline 1.75 & 2.42 & 0.92 & 71.25 & 27.02 \\
\hline 2.60 & 2.33 & 0.89 & 102.79 & 39.09 \\
\hline 1.67 & 2.51 & 0.65 & 70.5 & 18.44 \\
\hline 1.55 & 2.48 & 0.65 & 69.9 & 18.28 \\
\hline 2.43 & 2.39 & 0.7 & $\begin{array}{l}67.1 \\
\end{array}$ & 19.69 \\
\hline 2.07 & 2.88 & 1.143 & 81 & 32.17 \\
\hline 1.86 & 1.54 & 0.96 & 48.48 & 29.92 \\
\hline \multicolumn{5}{|l|}{ Averages } \\
\hline 1.805 & 2.31 & 0.88 & $\begin{array}{l}70.67 \\
\end{array}$ & 26.9 \\
\hline \multicolumn{5}{|c|}{ Standard deviations } \\
\hline 0.3858 & 0.57 & 0.15 & 22.21 & 6.81 \\
\hline
\end{tabular}

Error analysis:

Analysis considering the standard deviation of the whole data set

$$
\begin{array}{ll}
\Delta \mathrm{Q}_{\mathrm{h}} / \mathrm{Q}_{\mathrm{h}}=0.324441 & \sqrt{ }\left(\Delta \mathrm{T}_{\mathrm{h}} / \mathrm{T}_{\mathrm{h}}\right)^{2}+(\Delta \mathrm{V} / \mathrm{V})^{2}=0.324441 \\
\Delta \mathrm{Q}_{\mathrm{d}} / \mathrm{Q}_{\mathrm{c}}=0.253008 & \sqrt{ }\left(\Delta \mathrm{T}_{\mathrm{c}} / \mathrm{T}_{\mathrm{c}}\right)^{2}+(\Delta \mathrm{V} / \mathrm{V})^{2}=0.253008
\end{array}
$$




\section{RESUME \\ Sumeeth Sivanagere \\ 1064VanVoorhis road, Apt J120, Morgantown WV \\ (304)-293 5328; sumeeth ss@,hotmail.com}

\section{OBJECTIVE:}

Looking for a challenging opportunity to grow and prove my analytical, research skills that would enable me to learn new technologies and be an asset to the organization

\section{HIGHLIGHTS:}

- 2+ years of excellent engineering research experience in Experimental Fluid Mechanics, Fluid Flow Modeling, Thermodynamics, Heat Transfer and Design

- Has demonstrated excellent project management and inter-personal skills

- Apt in Microsoft Word, Microsoft EXCEL, AutoCAD 2000, ANSYS and IDEAS

- Ability to work under tight schedules and complete the task well ahead of time with dedication keeping quality in mind

- An excellent team player, highly motivated and a self-starter

\section{EDUCATION:}

M.S. Mechanical Engineering, (January '00-March '02) West Virginia University, Morgantown, WV

GPA: 3.50/ 4.00

B.E. Mechanical Engineering, (August '94-August '98), University of Bangalore, India

GPA: 3.75/ 4.00

\section{COURSE WORK:}

Dynamics of Viscous Fluids, Advanced Vibrations, Gas Dynamics, Instrumentation In Engineering, Advanced Thermodynamics, Heat and Mass Transfer, Computer Aided Design and Applications, Numerical Analysis using MATLAB, C++ Programming, Applied Linear Algebra, CAD/CAM and Robotics, Control Engineering, Mechanical Engineering Design And Drawing, Applied Thermodynamics, Fortran Programming, Applied Electronics and Microprocessors, Kinematics and Dynamics of Machines

\section{EXPERIENCE:}

Graduate Research Assistant

IMSE, West Virginia University

(July 2002-Present)

Responsibilities:

- Employing PIV to determine flow characterstics at different locations for a mannequin exposed to tracer gases

- Automate the air sampler and to control the suction and exhaust precisely

- Automate the data acquisition and control using a data logging program

Graduate Research Assistant

MAE, West Virginia University

(June 2000-June 2002)

Thesis: Experimental study of Thermosiphon performance 
- Designed and fabricated single phase rectangular loop thermosiphon that is magnet-ready test bed

- Automated temperature data acquisition with Q-BASIC data logging program

- Acquired velocity data using Laser Doppler Velocimeter (LDV) system and TSIFIND software

- Recorded and analyzed temperature and heat transfer coefficient data for gravity-driven flows

- Analyzed and compared the non-magnetic experimental data with a one-dimensional theoretical model of a single phase loop thermosiphon

\section{INTERNSHIP:}

\section{Research Engineer}

Liquid Propulsion Systems center, Indian Space Research Organization, India

(June 1997-July 1998)

\section{Design of Propeller Gauging System}

- Extensive study of different kinds of flow measuring devices used to control and manipulate fuel flow in a space shuttle

- Analyzed the various parameters that control the efficiency of flow measuring device under microgravity environmental conditions

- Designed the flow measuring device for optimum performance

- Prepared the experimental setup and tested for ground level accuracy and performance

\section{PROJECTS:}

Analysis of the effect of contact and axial stresses on a helical gear tooth

- Designed and modeled a helical gear pair using IDEAS

- Analyzed the effect of contact and axial stresses and the areas of stress concentration on the gear tooth

- Optimized the geometry of the gear pair for a given set of boundary conditions

\section{Simulation and analysis of the failure of a concrete slab}

- Modeled a concrete slab with variable yield strength using IDEAS

- Analyzed the modes of failure under variable boundary and loading conditions

- Optimized the geometry for the maximum external loads

\section{COMPUTER SKILLS:}

\section{Software}

Operating Systems: Windows 95/98, Windows 2000/NT, Unix, MS-DOS

Languages: C, C++, BASIC, Q-BASIC, Fortran, HTML, MATLAB

Databases: SQL Server, FoxPro, FoxBASE

Packages: AutoCAD R12, R14, 2000, IDEAS, ANSYS

Spreadsheets and Applications: Microsoft Word, Microsoft Excel, Microsoft PowerPoint

Hardware

Building microcomputers, A/D boards, Data acquisition boards

\section{PUBLICATIONS:}

J. Kuhlman, D. Gray and S. Sivanagere, "Performance of a Thermosiphon," presented at West Virginia Academy of Science, 2002 Annual Meeting, West Virginia University, Morgantown, WV, April 2002

\section{ACHIEVEMENTS:}


- Received National-level meritorious scholarship for all three years of higher secondary school (1989-1992)

- Received best student award and certificate of merit in junior year of under graduate school

- Captained my undergraduate institution in Cricket for 4 years (1994-1998)

- Placement Secretary, Mechanical Engineering Association, India (1998-1999)

- Secretary, Managed the Student Organization Committee, which was primarily engaged in Event Management, Bangalore University, India

\section{References available upon request.}

